Article

\title{
Optimization of Electric Vehicle Charging Points Based on Efficient Use of Chargers and Providing Private Charging Spaces
}

\author{
Lukáš Dvořáček *), Martin Horák (D, Michaela Valentová and Jaroslav Knápek \\ Department of Economics, Management and Humanities, Faculty of Electrical Engineering, Czech Technical \\ University in Prague, 16627 Prague, Czech Republic; horakm11@fel.cvut.cz (M.H.); valenmi7@fel.cvut.cz (M.V.); \\ knapek@fel.cvut.cz (J.K.) \\ * Correspondence: dvoral14@fel.cvut.cz
}

Received: 23 November 2020; Accepted: 16 December 2020; Published: 21 December 2020

check for updates

\begin{abstract}
Electric vehicles are a mobility innovation that can help significantly reduce greenhouse gas emissions and mitigate climate change. However, increasing numbers of electric vehicles require the construction of a dense charging infrastructure with a sufficient number of chargers. Based on the identified requirements for existing electric vehicle users and potential new customers, the paper proposes a charging point model for an urban area equipped with a local transformer station and a sufficient number of low-power chargers. In particular, the model focuses on efficient use of chargers throughout the day, considering private rental of chargers paid by residents in the evening. The model uses an optimization method that compares the non-covered fixed costs due to unsold electricity to nonresidents and the annualized costs of building an additional transformer. The proposed optimal charging point solution was tested in a case study using real data capturing users' habits and their arrivals in and departures from the car park. As our model results show, the great benefit of a park-and-ride car park equipped with chargers consists of a simple increase in car park efficiency, ensuring sufficient numbers of private charging lots, optimizing operating costs, and supporting the development of electromobility.
\end{abstract}

Keywords: shared parking; sharing economy; P + R car park; low-power chargers; electric vehicle

\section{Introduction}

Following the European Union (EU) 2030 targets [1], many subsidy programmes have been drawn up to support electric car sales and construction of charging stations [2]. Notably, support for sale of electric vehicles in many countries has caused rapidly growing numbers of electric vehicles (EV) in operation [3], which have swiftly overtaken the numbers of charging stations built [4]. To achieve a balanced ratio between electric vehicles in operation and charging stations, we need to step out of the vicious circle [5] where many investors wait with construction of charging stations because the number of EVs in operation has not achieved the required level. Conversely, many potential new EV owners wait for the numbers of charging stations to increase.

However, construction of public charging stations itself is not enough [1]. Due to the expected increase in the numbers of EVs, their owners will require similar parking and charging comfort that is typical of the owners' private garages or parking spaces [2]. Therefore, sharing them seems to be a smart and simple solution to ensure a sufficient number of parking and charging stations for electric cars.

Concerning the issue of sharing parking and charging places, some studies focus on peer-to-peer (P2P) sharing, cf. [2-4]. The disadvantage of the proposed P2P solutions can be seen mainly in the 
difficulty of ensuring the quality of the services provided. However, not all charging station owners are sufficiently conscientious and aim at ensuring high quality of the services. Usually, the charging station owner is responsible for their charging station failure, but not penalized in any way for it [4].

Another key issue associated with P2P sharing of charging stations is ensuring electricity grid stability. The electric grid can be in jeopardy mainly when the many shared charging stations in urban areas are fully occupied [5-7]. The methods used to smooth the peak load as a method of dividing the charging power between several charging stations cannot be used, because the charging station does not constitute one microgrid. Moreover, P2P charging station sharing does not provide a clear answer to the issue of procuring private charging points for EV users. Instead, it focuses on recharging EVs during the day. EV sharing assumes that the charging station will be used in the evening by the charging station owner who typically returns from work [6].

A good base for dealing with the issue of private charging stations is the idea of sharing parking places near commercial buildings [8,9]. Assuming that car parks with a high concentration of vehicles will be equipped with a sufficient number of charging stations, mainly due to the growing trend of electric cars, the possibility of sharing these places as private parking spaces for EV users offers itself directly. These places, equipped with charging stations, are mainly occupied during working hours. Beyond working hours, they are unused and thus offer the opportunity to create private charging points for EV owners.

Assuming these two conditions, i.e., charging stations connected to a microgrid and long EV parking times, the power division or charging shifting method [6] can be used to smooth the peaks in electricity consumption. In extreme cases, it is possible to supplement the microgrid with battery storage to further support the stability of the entire system and of the local electric grid.

The aim of the present paper is to offer a solution to one of the most common obstacles of potential EV users deciding whether to buy an electric car: the absence of a private charging space. Therefore, it is necessary to provide these users with similar charging comfort to what users with private home charging have, and to offer a price similar to that of home charging. We do so by defining the following research questions:

1. Can evening reservation of car parks equipped with low-power chargers in a $P+R$ car park compete with home charging in terms of both costs and charging comfort?

2. Is it essential to equip $P+R$ car parks with fast charging stations, due to the mode of using this type of car park and the time users park their EVs in this type of car park?

3. Is it possible to ensure that EV owners having no private garage and charger will have a fully charged EV battery before the next journey and the same comfort as users having a private garage and charger?

4. Is it possible to ensure for EV owners having no private garage and charger a price per $\mathrm{kWh}$ similar to users having a home charger?

The major contributions of this paper are as follows: (1) the problem of insufficient numbers of charging stations can be solved by effective use of existing car parks equipped with low-power chargers; (2) charging electric cars with low-power chargers contributes to efficient use of transformer station potential; (3) by reserving parking places in a car park during evening hours, it is possible to achieve higher efficiency of their use and simultaneously create charging conditions and a price per kWh comparable to home charging.

The rest of this paper is organized as follows. Section 3 analyses EV drivers' charging behaviour and proposes a model of sharing parking places in a $\mathrm{P}+\mathrm{R}$ car park equipped with low-power chargers. Section 4 presents a case study based on both the real occupancy of a $P+R$ car park and the real charging requirements of EV users, with the objective to optimize the installed power of transformer stations and the number of chargers used simultaneously from the technical and economic point of view. Section 5 presents the results of technical and economic optimization of the car park model, followed by discussion in Section 6 and conclusions with suggestions for future research in Section 7 . 


\section{State of the Art}

There are several aspects that potential customers consider when deciding whether to purchase an electric vehicle (EV). Firstly, the high investment costs of EVs are seen as the major barrier to EV scale-up $[2,3,6,10]$. Furthermore, the high initial investment in EVs currently sold correlates with the users' annual income. Xu et al. [6] stratified the percentage distribution of EVs registered in California into user groups with annual incomes above and below USD 150,000. The group of registered EVs in the group of users with an annual income exceeding USD 150,000 makes up 45\%. However, the percentage of registered EVs in the larger group of users with an annual income lower than USD 150,000 is only $15 \%$.

Individual countries try to compensate for this barrier using various financial instruments. The structure and scope of the financial instrument and its implementation varies from country to country. Additionally, not all countries provide subsidies for non-business vehicles. A questionnaire conducted in the Nordic region (Iceland, Sweden, Denmark, Finland, and Norway) shows that users would prefer a tax relief to a financial subsidy when purchasing EVs [3] with the exception of Sweden, where the government has taken several reform steps since 2006 to reduce the tax burden [11], which included the abolition of the most criticized taxes on real estate and property, also including cars. Conversely, Sweden has significantly increased its fuel tax since 2014 to support $\mathrm{CO}_{2}$ reductions and also increased the number of EVs in operation [11]. Other financial benefits that users will receive from EV, cf. [2,3], are free parking in restricted areas, free use of motorways, and an exemption from road tax if required by a particular country.

The second important issue for potential EV users is a short range of the EVs due to the small capacity of the installed batteries. The study [4] states that the average daily distance travelled by a user living in Beijing is $50 \mathrm{~km}$. Users living in California travelled less than $48 \mathrm{~km}$ by car during the day [6]. Respondents from the Nordic countries were also concerned about the short range of the EV, but finally, they stated that most of them were satisfied with an EV that would be able to achieve roughly 200 to $300 \mathrm{~km}$ per charge [3]. Only a minority of respondents would decide to purchase an EV only if the capacity of its battery allowed them to achieve a distance of at least $500 \mathrm{~km}$ [3].

Taking into account all currently available battery electric vehicle (EV) models, the average installed battery capacity is $61 \mathrm{kWh}$ [12], and the average energy consumption is roughly $19 \mathrm{kWh} / 100$ $\mathrm{km}$ [13]. The real range that EVs are able to achieve with one battery charge is approximately $314 \mathrm{~km}$ [14]. As can be presumed, the capacity of an installed electric vehicle battery strongly correlates with its purchase price [15]. However, EVs with a low purchase price will achieve $50 \mathrm{~km}$ per battery charge without difficulty. Even a two hundred-kilometre journey with a single charge is not unrealistic for them.

The third important issue for many respondents is charging electric cars and the question of a dense network of charging stations $[2,3,6,10,16]$. The questions in the questionnaire which focused on charging efficiency, charging station locations and network density are in line with current scientific issues addressed in the literature [1,4,8,9,17-23]. The issue of electric car charging can be principally divided into two main subcategories: home charging and public charging stations.

Home charging stations paved a new way for EV users, who are thus able to recharge their cars very comfortably. One of the most significant benefits of home charging of electric vehicles is a lower price per $\mathrm{kWh}$ compared to a business fast-charging station [24], together with a higher degree of comfort and less time spent charging on public charging sites, cf. [3,4,24,25]. On the other hand, the disadvantage of the home charging solution is the necessary upfront investment in the home charger set and, surely, also an investment in one's own parking place or garage, cf. [2,4,26].

However, not all users (especially in urban areas) have their own garage or parking place [4]. A dense network of charging stations is often a good bonus for $\mathrm{EV}$ users and a quick way to recharge their car during daily travel [3], but generally, EV users prefer home charging [3,6,27]. A private parking place or garage that provide EV users with the ability of charging an electric car was very important for potential new EV users, cf. [2-4]. For instance, Zhao et al. [4] describe the ratio between 
the number of registered EVs and the number of private charging stations in Beijing. In 2017, a total of $124,000 \mathrm{EVs}$ were registered, and $67 \%$ had their private charging stations. The remaining $33 \%$ of EVs were dependent on recharging using public charging stations. Most of the population in cities live in flats without a private garage or a private parking place [26]. These larger groups of users leave their cars in public car parks near their apartments. They do not usually have the possibility of buying a home charging set and using it to charge EVs [4]. Furthermore, in these densely populated areas, a problem arises not only with a lack of private parking places and garages but also with a lack of free public car parks, cf. $[1,2,4,8,9,23,28]$. The sharp increase in the number of cars and the expected increase in the number of EVs [29] in future means that there will be a lack of new parking places [9]. Very often, it is not possible to build new car parks in the required location at all, or it is not economically viable [30].

From a global perspective, the lack of parking places is not caused by a physical shortage of car parks, but by inefficient use of existing ones. In particular, corporate car parks, parking spaces near commercial buildings, post offices, hospitals, schools, shopping centres and banks are busy mainly during working hours, cf. [8,9,23]. Cai et al. [9] estimate that the percentage utilization of these parking spaces in Beijing during the day is approximately $50 \%$. At night, the utilization decreases further to $40 \%$.

Increasing the efficiency of use of existing car parks is therefore crucial. Several optimization methods have been used so far. Perhaps the most straightforward and now well-established method for increasing the efficiency of car parks is to reserve a particular parking place for the required time interval [30]. Friesen and Mingardo [30] focus on increasing the efficiency of car parks using a method based on revenue management and dynamic parking. This method adjusts the price of parking to the car park location, the time of day when a customer parks their vehicle, and the day of the week. Friesen and Mingardo [30] and Lei et. al. [31] came to a very similar conclusion in their studies: the dependence of users' demand for parking places depends on changing prices of parking.

Cai et al. [9] present the optimum method of sharing the same area from the perspective of car parks and users at administrative buildings. To ensure the same occupancy of individual car parks, they recommend approximately equal distances of car parks from points of interest. Better management of the occupancy of individual car parks can also be achieved by changing the price of parking. A problem may occur in residential car parks of office buildings with highly sought-after locations, where, even after the increase in the parking fees, there are still problems with lack of free parking places [9]. These car parks cannot, however, be shared with nonresidents. The authors further state that a choice of car park is negatively influenced by the parking fee, travel time, risk of no parking space, and general obstacles to parking [9].

Similarly, Huang et al. [8] agree that an effective way to solve the problem of the lack of parking spaces is not their new construction, but more efficient use of existing ones. The main research objective was to determine the optimum number of shared parking places for the car park assumed. Assuming that the demand for parking spaces is constant and greater than the number of parking spaces provided, they conclude that the optimum number of reserved places is approximately equal to half the proportion of long-term parking users. However, it can be assumed that the number of parking places offered for sharing will depend mainly on the car park location related to the demand for the given location.

Similarly to the lack of car parks, the lack of charging stations for EVs is perceived as a significant obstacle, cf. $[2,4,23,28]$.Sharing of existing charging stations could eliminate the vicious circle between public charging station infrastructure developers and potential EV owners [2]. From the economic point of view, the development of a dense network of public charging stations depends on increasing numbers of EVs in operation, and new EV users are often discouraged by small numbers of charging stations [2]. The incentive not only for the investor to build a dense network of charging stations is supported by the European Commission which, supports the Europe-wide electromobility initiative and Green eMotion projects with an approximate amount of EUR 41.8 million [32]. 
The use of existing private charging stations is inefficient, cf. [4]. EV owners usually use private charging stations in the evening and the station remains used inefficiently during the day [4]. Therefore, optimizing the use of charging stations by sharing them results in benefits not only for the charging station owners but also for other users of electric cars who could then use the dense network of charging stations $[3,6,18,19]$.

Plenter et al. [2] dealt with the development of "CrowdStrom," representing a peer-to-peer (P2P) sharing and collaborative transportation consumption service for private charging infrastructure by using information technologies. These authors specify three main factors that an individual must ensure to provide his charging point for other EV users. The first important factor is the owner's willingness to share their charging station with other users. The second necessary factor is to ensure free access to the charging station (which tends to be an issue, especially in private underground garages of condominiums, where only renters have primary access). The third, final factor is internet connection, important for sharing information about the station occupancy. In addition to an IT solution, the authors also asked residents about their willingness to participate in a charging station sharing project. From a total sample of 327 respondents, $45 \%$ indicated above-average interest in becoming a provider regularly offering private charging stations to the public. However, a more detailed analysis of the questionnaire data showed that only 450 shared charging points would be created in a given locality with 300,000 inhabitants. The estimate was based on the answers of respondents who had the opportunity to build a parking place and add a charging station. Additionally, with above-average interest, they had to agree with purchasing an EV and providing the charging station for other EV users.

The results of the questionnaire [2] also show that people have a better chance of sharing private charging points in suburban areas because they are more likely to have their own parking place and to equip it with a charger. Zhao et al. [4] had a similar idea of sharing private charging stations with other users. The analysis found out that the utilization rate of private charging stations in Beijing was $4.5 \%$. By offering these private charging stations to other users, their utilization rate has increased by $0.4 \%$. The main limitation to the study by Zhao et al. is that the charging station owners provide their charger for other EV users during the daytime, but not in the evening, when the owner occupies the charging station. We take the opposite approach. Sharing of parking places in a P + R car park, which are unused at night-time, correlates with EV users' demand for charging in the evening, when they usually return home from work.

$\mathrm{Xu}$ et al. [23] approach sharing of parking places and charging stations from a different angle than the two abovementioned studies. They consider sharing parking places primarily in a car park in a commercial building. The pairing of parking place owners and customers then proceeds as follows. Each parking place owner sets a minimum price of renting in the time interval when they do not use it and each customer suggests the maximum price they are willing to pay for parking. An important factor of pairing is that the parking place owner is assigned a customer who offered the same or higher price of renting the parking place. Customers' fees consist of renting a parking space and the electricity consumed. However, the customers can get a financial benefit if they opt for demand-side management (DSM). The DSM method is used to optimize the parking costs by modifying EV charging/discharging behaviour. DSM aims at encouraging consumers to use less energy during peak hours, or to shift their energy use to off-peak times such as night-time and weekends [23].

Many studies [2-4] state that owning a private parking place is often an important condition for deciding to purchase an EV. In urban areas, where there is a limited number of public parking places, the possibility of sharing offers itself directly. Car parks near commercial buildings, post offices, hospitals, schools, and shopping malls are often the best possible solution for sharing, as the studies show. Especially beyond working hours, these car parks are used with low efficiency.

The research gap to which this article responds is effective use of parking spaces near commercial buildings, shopping malls, hospitals, etc. [2-4]. These car parks will be equipped with a sufficient number of chargers due to the expected increase in EVs, resulting in a high concentration of cars in the working hours when these institutions are most busy [2]. Furthermore, these car parks are very often 
located near settlements. Therefore, it offers itself directly to provide these car parks equipped with a charger for EV owners living close by. Rental of these charging points then offers private charging points for EV users without a garage or home charger.

Furthermore, our article solves the problem of the absence of a private parking place equipped with a charger, which often dissuades potential customers from buying an electric car [2]. This research presents a $\mathrm{P}+\mathrm{R}$ car park model equipped with a sufficient number of chargers. It is assumed that $\mathrm{P}+\mathrm{R}$ car parks are used mainly during the day and at least in the evening. Plenty of available charging points in the evening also correlates with EV users' demand for charging in the evening, when they usually return home from work. Thus, the proposed solution directly solves the problem of many potential EV users who do not have their own private charging points, a factor that often discourages them from buying an EV [2-4].

\section{Model of EV Charging in Shared Parking Places}

EV users come mainly from urban areas with a high proportion of apartment buildings, so they often face not only a lack of places for charging, but also places for private parking. Thus far, many charging models have focused on home and public charging, and similarly, there have already been many general ways of sharing parking places $[2,4,8,23,28]$. The proposed model combines the above approaches and models by building charging infrastructure in an existing car park and introduces the concept of sharing it. In order to increase the efficiency of use, the model contains parking places and charging infrastructure not only for residents living around but also for those randomly arriving in the daytime.

The model aims to design a technically and economically optimal solution for additional installation of $3.6 \mathrm{~kW}$ AC chargers and other necessary energy equipment in an existing car park. The model focuses on sharing parking places from the car park operator's perspective, trying to offer comfort and service for EV users comparable to home charging. Simultaneously, the model aims to guarantee low-power night-time charging for users' EVs, which will sufficiently compete with public fast-charging stations and achieve low-priced home charging.

\subsection{User Description}

A key issue in setting up a model of a car park equipped with chargers is to dimension and adapt its equipment to the requirements of individual groups of electric car users. Generally, car park users can be divided into two main groups. The first group consists of randomly arriving EV users who commute to the site for work or other purposes. The other group comprises users (residents) who live close to the car park and rent a parking place primarily for charging. Residents are offered a level of comfort similar to that of people living in family houses and having their own garage equipped with a charger.

Our model assumes that the first group of EV users (nonresidents) use the car park primarily in the daytime. The purpose of daytime parking might be the vicinity of a shopping centre or means of public transport. Therefore, nonresident users' priority is parking rather than charging. Although the price is close to home charging, charging is not mandatory for nonresidents. Before parking, each nonresident user chooses whether they want to charge the EV. After leaving the parking place, the user pays not only an appropriate hourly parking rate but also the energy bill. Since the car park is not primarily intended as a public charging site, nonresidents are not guaranteed recharging during their whole parking time. Parking only increases the energy level in the EV; the problem of full recharging is solved by home charging or other means.

For the second group (residents), the car park model offers the possibility of renting parking places with a charger. The parking places are reserved for the residents on weekdays during the night-time. At weekends, resident parking places are also reserved for the residents throughout the day. If the residents arrive no later than at the set evening time $\left(T_{l}\right)$, they are guaranteed a sufficient number of charging hours correlated with recharging an appropriate amount of energy. However, the rules for 
the resident group require different settings. It is assumed that the residents want to rent a parking place mainly due to the absence of private parking and charging places.

Compared to nonresidents, residents are financially motivated to use car parks to charge their EVs. The principle of incentives we propose consists in the introduction of a minimum flat rate for residents including guaranteed charging hours, regardless of the actual use. Charging after the guaranteed hours is then calculated per $\mathrm{kWh}$. The flat rate will ensure a reduction in the risk of non-covered fixed costs (NCFC) due to a blocking car with little need for charging. Another source of risk is mutual blocking of users; this is addressed in the following chapter.

\subsection{Blocking Issues}

To completely prevent charger blocking, additional installation of chargers in each parking place is assumed. The problem of sharing parking places between groups is addressed by resident membership booking for a specific day. Here, a resident does not have the option to rent a particular parking place but can book membership in a parking group. Since overlaps can occur in the case of a nonresident's or a resident's delayed departure, the calculation takes into account an overlap around the morning $(X)$ and evening $(Y)$ hours, when the overlaps are the most frequent. Above all, the model takes into account a capacity reserve $\left(Q_{r}\right)$.

$$
Q_{r}=Q_{p l}-Q
$$

where $Q_{p l}$ is the total number of parking places in a car park and $Q$ is the number of parking places reserved for residents.

For a resident who decides not to leave, the resident daytime tariff is charged. In the case of a resident staying in the daytime, the minimum tariff rate $\left(R_{\text {resident }}\right)$ is set as the product of the NCFC per unsold $\mathrm{kWh}\left(L_{p_{-} k W h \_n o n r e s i d e n t}\right)$, the average occupancy of the charger $\left(T_{o}\right)$, and the charger $\left(P_{C H}\right)$.

$$
\begin{gathered}
R_{\text {resident }}=L_{p \_k W h \_n o n r e s i d e n t} \cdot T_{0} \cdot P_{C H} \\
L_{p \_k W h \_n o n r e s i d e n t}=L C O E_{\text {nonresident }}-N_{\text {var }}
\end{gathered}
$$

where $L C O E_{\text {nonresident }}$ is the levelized costs of electricity for the nonresident group, and $N_{v a r}$ is the marginal price per $\mathrm{kWh}$.

For a nonresident who does not leave until the last daytime parking hour, the night-time nonresident tariff is charged. In the case of a nonresident staying overnight, the minimum tariff rate $\left(R_{\text {resident }}\right)$ is set as the product of the NCFC per unsold $\mathrm{kWh}\left(L_{p_{-} k W h_{-} \text {resident }}\right)$, the guaranteed resident charging hours $\left(T_{g}\right)$, and the power of one charger $\left(P_{C H}\right)$.

$$
\begin{aligned}
& R_{\text {nonresident }}=L_{p_{-} \_W h \_ \text {resident }} \cdot T_{g} \cdot P_{C H} \\
& L_{p \_} k W h_{\_} \text {resident } \\
& =L C O E_{\text {resident }}-N_{\text {var }}
\end{aligned}
$$

where $L C O E_{\text {resident }}$ is the levelized costs of electricity for the resident group, and $N_{\text {var }}$ is the marginal price per kWh.

\subsection{Charging Scheme}

Nowadays, building power infrastructure with a minimum charging output $50 \mathrm{~kW} \mathrm{DC}$ is most common if short charging times are to be achieved. Furthermore, construction of charging infrastructure requires installation of either more local transformer stations or higher-power stations. It is also necessary to increase the capacity of the high voltage (HV) connection and increase the reserved power. The time of utilization of the installed capacity is short in this case. From the economic point of view, especially the costs associated with the increase in the reserved power from the HV power grid are not viable. 
Contrarily, construction of charging infrastructure with low-power charging stations (usually up to 3.6 to $10 \mathrm{~kW}$ ) avoids these issues. The time of utilization of the installed capacity will increase, and the smoothness of consumption ensures predictability for purchasing electricity from the trader. Installing a low-power charger in each parking place (Figure 1) then appears to be a more advantageous option for this model.

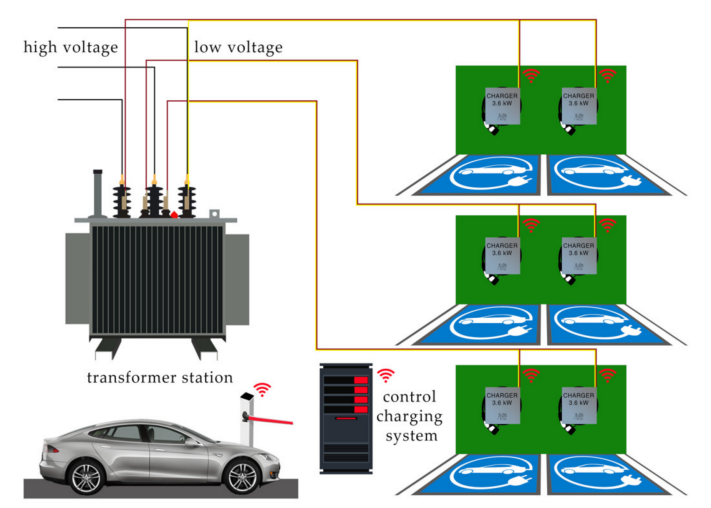

Figure 1. Car park model equipped with low-power chargers.

\subsection{Model Input Parameters}

The input parameters of the car park model equipped with low-power chargers are as follows:

- $\quad$ Maximum number of parking places in the car park assumed $\left(Q_{p l}\right)$;

- EV arrivals on weekdays with the highest demand for parking;

- $\quad$ Peak parking occupancy at the weekends $(Q)$;

- Data describing the demand for electricity by arriving EV users;

- Maximum number of residential parking places $\left(Q_{r}\right)$.

The model of charging infrastructure for an existing car park consists of a HV/LV transformer station, switch disconnectors and isolators, a circuit breaker, 16A fuses, cabling, a heat exchanger (cooler), a charging control system, and chargers.

\subsection{Dimensioning the Transformer Station Power}

The charging issue is always related to the maximum load of one or more locally installed transformers. The minimum power $(P)$ of a transformer station is based on the total requirement for recharging the residents' EVs $\left(E_{r}\right)$. Residents' recharging requirements are defined by the probability density function (PDF) of their daily mileages $\left(F\left(T_{g}\right)\right)$. Based on the charger power of $3.6 \mathrm{~kW} \mathrm{AC}$ and the given percentile of charging success $(p)$, a minimum charging time $\left(T_{g}\right)$ obtained should be guaranteed for residents. Simultaneously, information about the total energy needed for recharging $\left(E_{r}\right)$ is obtained from the PDF of resident daily mileages.

To verify whether power of a group of installed transformers is sufficient, the model compares energy needed to charge the residents' EV $\left(E_{r}\right)$ and the energy that the local transformers can provide in the time interval reserved for residents $\left(E_{T R_{-} Y X}\right)$.

$$
\begin{gathered}
E_{T R_{-} Y X} \geq E_{r} \\
E_{r}=\sum_{x=1}^{Q_{r}} E_{r}(x) \\
E_{T R_{-} Y X}=P_{\text {ch_par }} \cdot(Y-X)[\mathrm{kWh}] \\
P_{\text {ch_par }}=\operatorname{ch}_{\text {par }} \cdot P_{C H}[\mathrm{~kW}]
\end{gathered}
$$




$$
c h_{p a r} \leq \frac{P}{P_{C H}}
$$

where $P_{c h \_p a r}$ is the power consumption of the entire array of chargers used simultaneously $c h_{p a r} . P_{C H}$ is the power of one charger.

The optimal number of local transformers should be the subject of economic analysis. The economic assessment also includes a comparison of NCFC due to electricity unsold to nonresidents, and annualized costs of building an additional transformer. If the NCFC exceed the annualized costs, it is advantageous to add another transformer to the transformer station.

\subsection{Charging Power Sharing Method}

An important issue in terms of charging is the distribution of the transformer station power $(P)$ among the individual EVs. Compared to residents, nonresidents arrive in the car park randomly during the time span from $(X)$ to $(Y)$.

The occupancy curve strongly depends on the type of car park. Therefore, the estimate of the number of arriving nonresidents in a given period must result from long-term observation. The PDF of the length of stay $(L)$ and the PDF of the quantity of arriving nonresidents in the given time intervals (A) are calculated from the observed data. As for the residents, we obtain information about the total energy needed to recharge their EVs $\left(E_{r}\right)$ from the PDF of resident daily mileages.

The main difference in the division of the power of a local transformer station among the nonresident group is that nonresidents do not have a guaranteed energy supply (Figure 2). Therefore, the power of a local transformer station is divided among the EV being charged. The number of EVs being charged $\left(c h_{\text {par }}(t)\right)$ and the number of new charging requests are monitored in the given time steps $(t)$. The limiting factor for accepting a charging demand is the remaining unused power of the transformer stations $\left(P-P_{c h \_p a r}(t)>0\right)$. In a situation where there are several requests for charging $\left(N_{w}(t)>0\right)$ and recharging of all EVs is impossible due to transformer station overload $\left(P_{c h \_p a r}(t) \geq\right.$ $P)$, the first-in, first-out (FIFO) basis is used. The charging of waiting EVs is postponed until they are guaranteed continuous charging. The EVs are then charged until either they have fully charged batteries, or their owners voluntarily interrupt charging and depart.

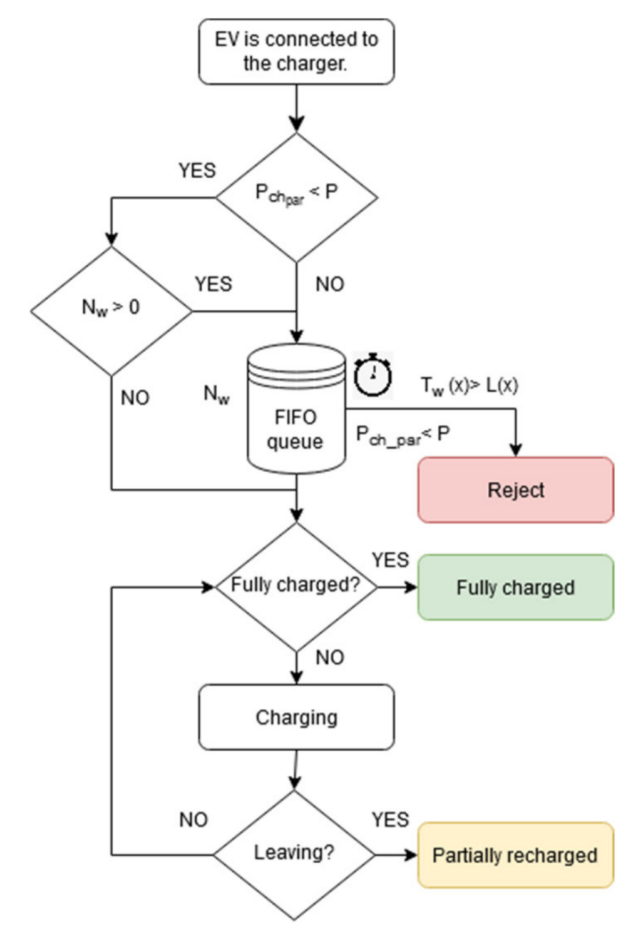

Figure 2. Nonresident charging diagram. 
Contrarily, the residents have guaranteed $\left(T_{g}\right)$ charging hours (Figure 3 ) as part of the parking rate, providing that they arrive between $Y$ and the last morning hour $\left(T_{l}\right)$. If the transformer station is not fully used and the battery of a resident's EV is not fully charged even after the guaranteed $\left(T_{g}\right)$ hours, the battery is charged further. An interruption in the charging of this car will occur at the moment of the full battery capacity or on the arrival of another resident who has not exhausted the charging hours guaranteed and if the simultaneous charging of both EVs would exceed the maximum power of the transformer station.

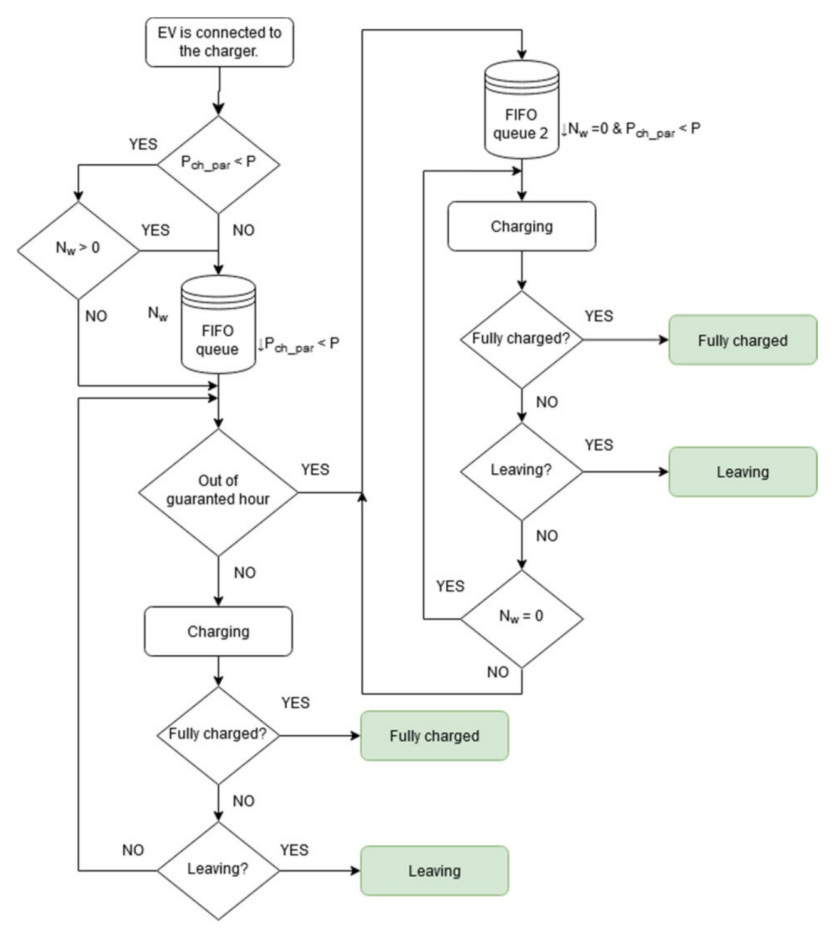

Figure 3. Resident charging diagram.

\subsection{Economics of System Dimensioning}

Apart from technical aspects, economic factors need to be taken into account when constructing a charging point. One of the key issues is the competitiveness of the project compared to other charging methods, such as using public fast-charging stations and home charging using a private charger. We assume that the main priority of the model is to create a sufficient number of shared parking places for residents and comfort and charging costs similar to home charging. Therefore, home charging is the main competitor for the car park with the charging infrastructure.

To assess the economic effectiveness, the model uses the levelized costs of electricity (LCOE) to recalculate individual capital expenditures (CAPEX) with different lifetimes and operating expenses (OPEX) converted to a unit price per $\mathrm{kWh}$. CAPEX involve a HV/LV transformer station, switch disconnectors and isolators, circuit breaker, fuses, cabling, heat exchanger (cooler), installation material, chargers, connection fee, installation work, and charging control system. OPEX are generally divided into two items, the first one consisting of maintenance and the second one associated with electricity consumption.

Since the transformer station causes the highest losses, the empirical formula given by CSN 341610 standard is used for the estimation of annual losses in the transformer station.

$$
T_{L}=\left[0.2 \frac{T_{m}}{T_{0}}+0.8\left(\frac{T_{m}}{T_{0}}\right)^{2}\right] \cdot T_{0}
$$


where $T_{L}$ is the annual time of full transformer losses, $T_{m}$ is the utility factor, and $T_{0}$ is the annual operating time of the transformer station.

$$
W_{L}=P_{n l} T_{o}+P_{k n} \frac{S_{m}^{2}}{S_{n}^{2}} T_{L}
$$

where $W_{L}$ is the annual energy losses in the transformer, $P_{n l}$ is the power transformer no-load loss, $T_{0}$ is the annual operating time of the transformer station, $P_{k n}$ is the short-circuit transformer losses, $S_{m}$ is the maximum apparent-power load of the transformer, $S_{n}$ is the apparent power of the transformer station, and $T_{L}$ is the time equivalent of losses at the maximum load of the transformer per year.

From a technical point of view, the power of one transformer installed in a transformer station may be sufficient for the full charging of residents' EVs, but the percentage of refused nonresidents and the associated unsold electricity can generate significant NCFC. A comparison of these NCFC with the annuity costs associated with an increase in the power of the local transformer station determines whether the increase is economically beneficial or not. The economics of system dimensioning aim at determining the levelized costs of electricity (LCOE) for both the nonresident and resident groups.

$$
\text { LCOE }=\frac{\text { sum of costs over lifetime }}{\text { sum of electrical energy sold }}=\frac{N_{i}+\sum_{t=1}^{n}\left(M_{t}+N_{E t}\right)(1+r)^{-t}}{\sum_{t=1}^{n} E_{t}(1+r)^{-t}}
$$

where the variable $N_{i}$ denotes the initial investment in the equipment; $M$ is the annual maintenance expenditures, $N_{E}$ is the electricity bill in the year $t, r$ is the discount rate, and $E$ denotes electricity sold in the year $t[\mathrm{kWh}]$.

The optimization method is based on economic cost evaluation. This method compares the NCFC due to electricity unsold to nonresidents and annualized costs of building an additional transformer. The optimization minimizes the number of refused nonresidents via installation of additional transformers. The algorithm applies a constraint that the overall costs of charging, including NCFC and annualized costs of building of another transformer, do not exceed $0.19 \mathrm{EUR} / \mathrm{kWh}$ (for both residents and nonresidents).

\section{Case Study}

The following chapter deals with an application of the model to real data. The chapter consists of four subchapters. The first and second present and analyse the real data entering the model. They are followed by technical evaluation of the case study data (third subchapter) and economic evaluation (fourth subchapter).

\subsection{Parking Place Input Data Analysis}

Data from a park and ride $(P+R)$ car park with 650 parking places in Prague Letñany were selected for the survey [33]. The data capture the car park occupancy in five-minute intervals from the 1st quarter of 2013 to the 4th quarter of 2016. The car park occupancy data do not include data for holidays and public holidays, which would alter the occupancy information for the given days significantly. The parking data do not include any private residents.

For further processing, the car park occupancy information for individual five-minute intervals was broken down into weekdays (from Monday to Friday) and weekends (Saturday and Sunday). The average occupation level in the corresponding five-minute interval was calculated for each day based on this four-year study.

Subsequently, an extensive analysis of the data was performed in order to identify significant differences in the car park occupancy between individual weekdays (Monday to Friday), and weekdays and weekends. The analysis of weekdays shows that the user behaviour is almost identical for Monday, Tuesday, Wednesday and Thursday. On Friday, the parking places were occupied significantly less. Considering that the occupancy in the individual five-minute intervals has a normal distribution with 
a $64 \%$ probability, the difference in the occupancy in the time interval from 7 am to $7 \mathrm{pm}$ on Monday, Tuesday, Wednesday, and Thursday is less than 3\% (Figure 4).

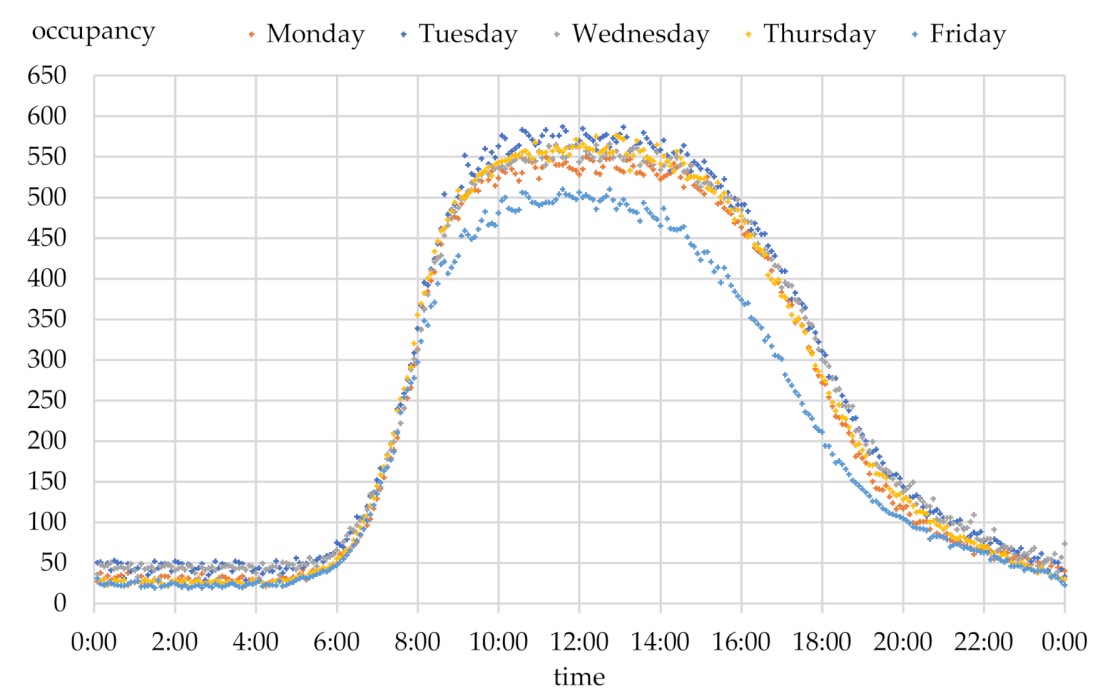

Figure 4. Occupancy on weekdays ([33], calculated by authors).

Moreover, an analysis was performed to identify changes in user behaviour depending on the quarter of the year. The analysis shows that the user behaviour remains almost unchanged throughout the year. For example, for Thursday, considering that the occupancy values in each five-minute interval have a normal distribution with a probability equal to $64 \%$, the difference in occupancy from 7 am to $7 \mathrm{pm}$ in the first, second, third and fourth quarters is less than $6 \%$ (Figure 5).

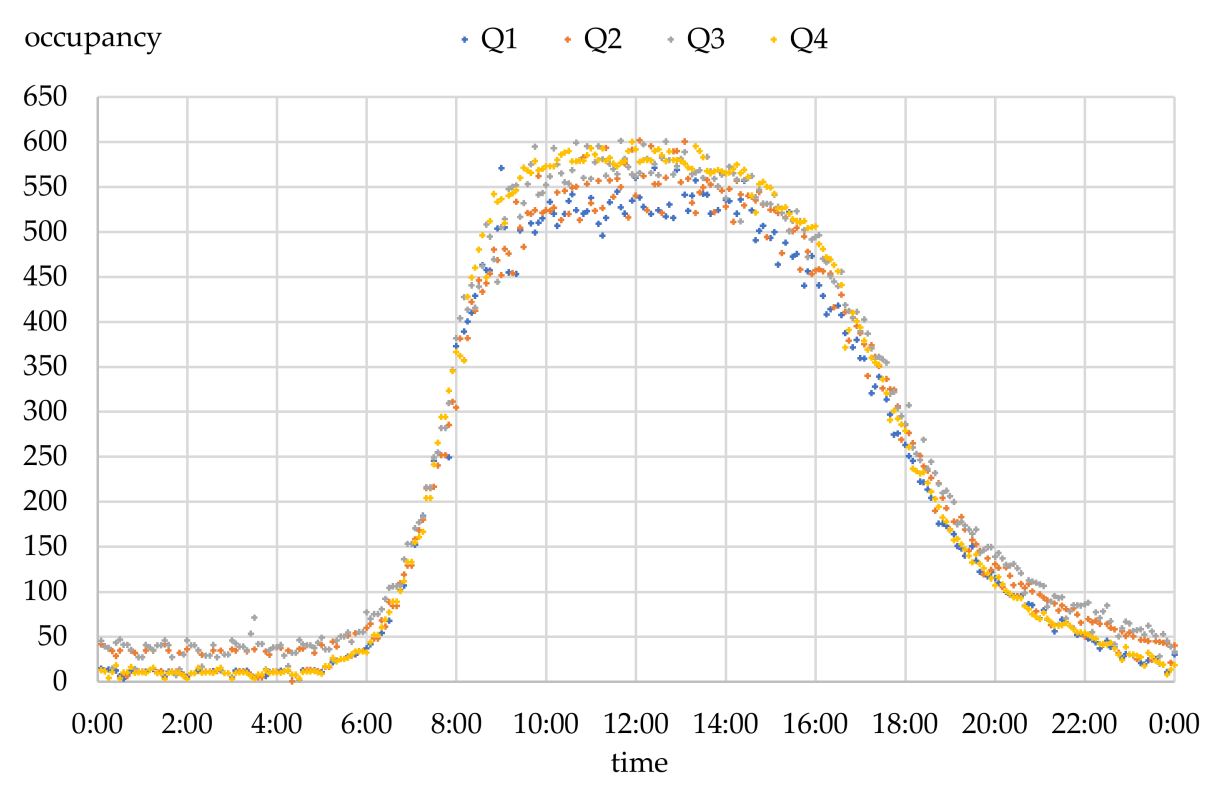

Figure 5. Thursday arrivals/departures ([33], calculated by authors).

Since the user behaviour in individual quarters and on weekdays, except Friday, was nearly the same, we selected the Thursday occupancy for further modelling. In terms of parking place occupancy, Thursday parking place occupancy has the character of the busiest weekday. Furthermore, the weekend car park occupancy analysis shows that the user behaviour on both Saturday and Sunday is the same in all the quarters. The average occupancy on these weekend days is constant, equal to 100 parking places. 
The disadvantage of the provided data describing only the car park occupancy is the loss of information on arrivals and departures within the measured five-minute interval; for example, arrivals and departures of the same number of cars in the same five-minute interval show a zero change in occupancy. Therefore, the Poisson distribution using random arrivals of individual cars was used to approximate the real car park occupancy. The departure time, which correlates with the parking time for a car in a parking place, was modelled using a Gaussian distribution with a $4 \mathrm{~h}$ mean and a standard deviation of $1 \mathrm{~h}$.

Data obtained from charging stations operated by ŠKO-ENERGO (Mladá Boleslav, Czech Republic) were used to simulate demand for recharging of electric vehicles [34]. During the three-month testing in 2020, data on 330 charging iterations from various types of EVs were obtained. The charging data were obtained from seven charging points, each equipped with a $22 \mathrm{~kW}$ DC power charger. At four of these seven charging points, it was also possible to use a $50 \mathrm{~kW}$ DC charger [34]. A more in-depth analysis of the data provided information about the time spent in the car park and the time required for sufficient charging. The analysis shows that users left the EVs parked and connected to the charger for a longer time than required to recharge the battery. This can be demonstrated by the fact that it is possible to recharge the battery of a EV more with a lower-power charger over the same parking time. Figure 6 shows that users park for longer than is needed to recharge the battery to full capacity, thus unnecessarily blocking the possibility of recharging other electric cars.

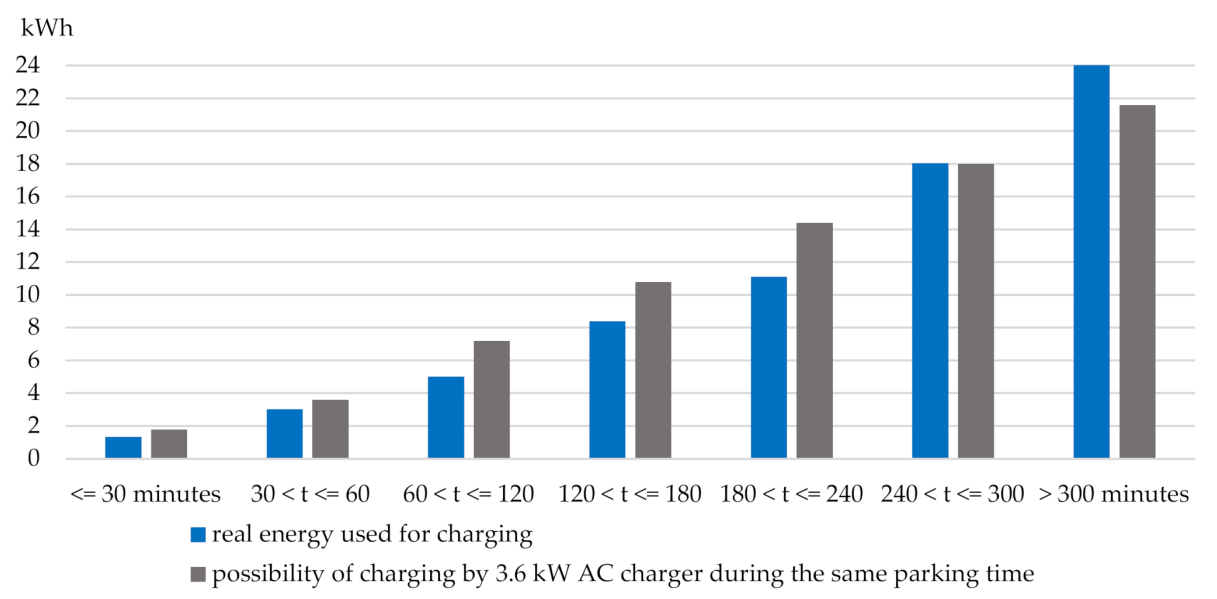

Figure 6. ŠKO-ENERGO charging stations ([34], calculated by authors).

Almost $90 \%$ of the car users analysed would have done with a shorter charging time to recharge the required energy or using a $3.6 \mathrm{~kW}$ AC charger to achieve the same recharging level in the same amount of parking time (Figure 6).

The EV charging sample also offers a valuable outline of the demand for electricity recharging. The data obtained from 330 charging iterations were sorted based on the energy consumed and subsequently used to calculate the cumulative distribution function (CDF) (Figure 7). The most frequent group (16\%) are EVs with an $11 \mathrm{kWh}$ charging requirement. The charging requirements show that $90 \%$ of arriving EVs require less than $18 \mathrm{kWh}$ to recharge, which corresponds to approximately $5 \mathrm{~h}$ of recharging with a $3.6 \mathrm{kWh}$ charger (Figure 7). 


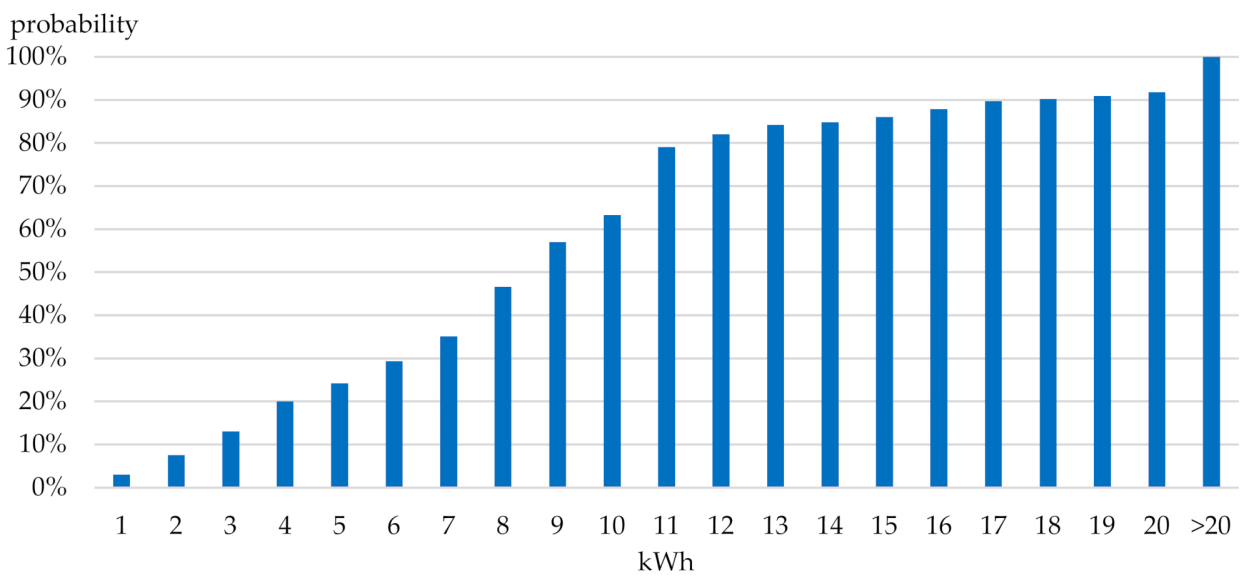

Figure 7. Cumulative distribution function of charging requirements [kWh] ([34], calculated by authors).

\subsection{Users Input Data Analysis}

The case study considers integration of charging infrastructure into an existing $\mathrm{P}+\mathrm{R}$ car park with 650 parking places $\left(Q_{p l}\right)$ in Prague Letňany. The real data analysis revealed that the average weekend occupancy of the car park $(Q)$ is 100 parking places. Therefore, 550 parking places $\left(Q_{r}\right)$ out of the total parking capacity of $650\left(Q_{p l}\right)$ can be reserved for residents. A more detailed analysis of the input data describing the car park occupancy set the residents' interval from $X=7$ am to $Y=7$ $\mathrm{pm}$. The input data vector describing the one-day car park occupancy is composed of 288 five-minute intervals. The number of predicted nonresidents who arrived in a given five-minute period $(A(t))$ is estimated using the normal distribution function. The mean value and standard deviation needed to calculate the normal distribution are achieved from the five-minute intervals, which correspond with both the day of the week and the placement of the five-minute period on a given day. (For example, the calculation concerning all the first five-minute periods obtained from each Monday.) Similarly, the time spent by a nonresident in the parking place is estimated using the normal distribution function, where the mean value equals to $4 \mathrm{~h}$ and the standard deviation is $1 \mathrm{~h}$.

The Poisson distribution was used to predict the demand for charging nonresidents $\left(E_{n}(x)\right.$ ), where $\lambda$ corresponds to the mean value of the data obtained from the charging stations operated by ŠKO-ENERGO.

The requirements for charging are described as follows:

$$
\begin{gathered}
\hat{A}(t) \sim N\left(\mu_{A}(\mathrm{t}), \sigma_{A}(\mathrm{t})\right) \\
L(x) \sim N\left(\mu_{L}, \sigma_{L}\right) ; \mu_{L}=4 \mathrm{~h}, \sigma_{L}=1 \mathrm{~h} \\
E_{n}(x) \sim \operatorname{Poisson}(\lambda) ; \lambda=8 \mathrm{kWh}
\end{gathered}
$$

where $\hat{A}$ denotes a vector with the distribution of arrivals of nonresidents in five-minute intervals during the day expressed by the average $\mu_{A}(\mathrm{t})$, and the standard deviation $\sigma_{A}(\mathrm{t})$. The variable $L$ is the length of nonresidential stay with a normal distribution with the average $\mu_{L}$ and the standard deviation $\sigma_{L}$. The last variable denotes a recharging requirement approximation by the Poisson distribution.

The case study for the resident group models the charging demand only. The charging demand is based on the study [35] focusing on the PDF of daily distance driven by car (Figure 8). The assumed demand for charging characterizes the residents' behaviour. They primarily charge their EV once a day after returning home, similar to most users with their own charger and a garage. The arrival curve and the time spent by the residents in the car park have not been accounted for. In the case study, we assume that a sufficient number of residents will arrive before the set time $\left(T_{l}\right)$ required for a guaranteed charge. 


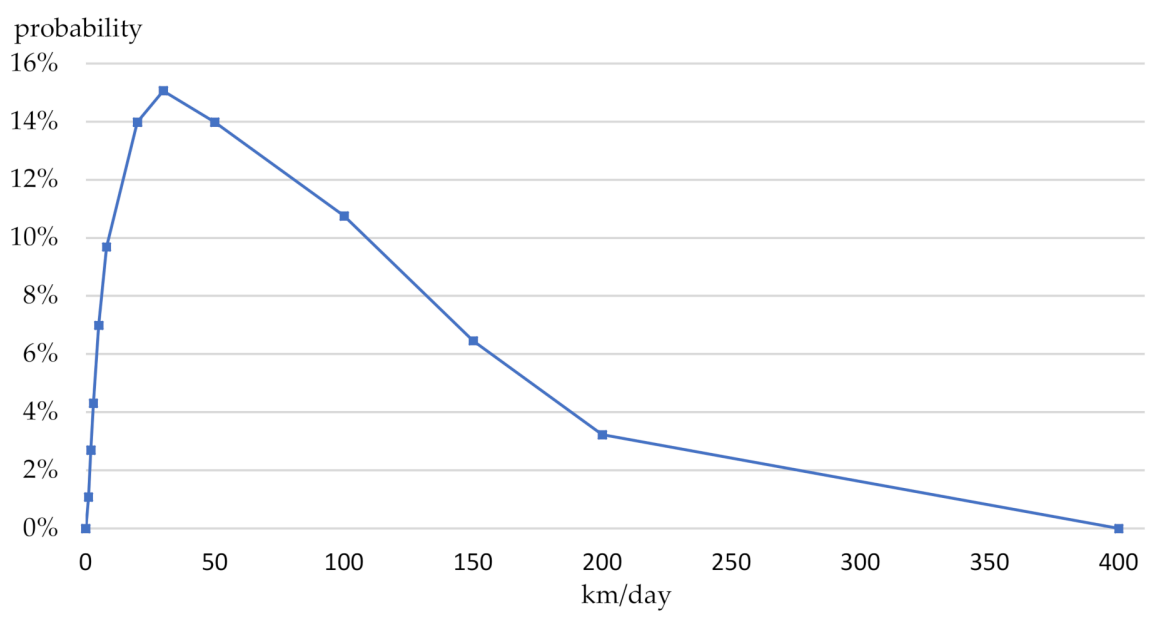

Figure 8. Probability density function of daily distance driven by car [35].

By dividing the daily distance driven by car and the average EV consumption by $100 \mathrm{~km}(19 \mathrm{kWh})$, we obtain information about the required energy charge. In order to charge energy, it is also necessary to take into account the compensation for electrical losses that occur during charging. A test of power consumption in electric cars [36] shows that EVs consume between 10 and 25 per cent more electricity than their onboard computers show. However, it can be assumed that charging with a low-power $3.6 \mathrm{~kW}$ AC charger results in the losses being closer to the $10 \%$ value. By dividing the charging power of the charger and the required charge energy $\left(E_{r}(x)\right)$, including losses during charging, we obtain information about the required charging time $\left(T_{r}(x)\right)$ (Figure 9).

$$
T_{r}(x)=\frac{E_{r}(x)}{3.6 \mathrm{~kW}}
$$

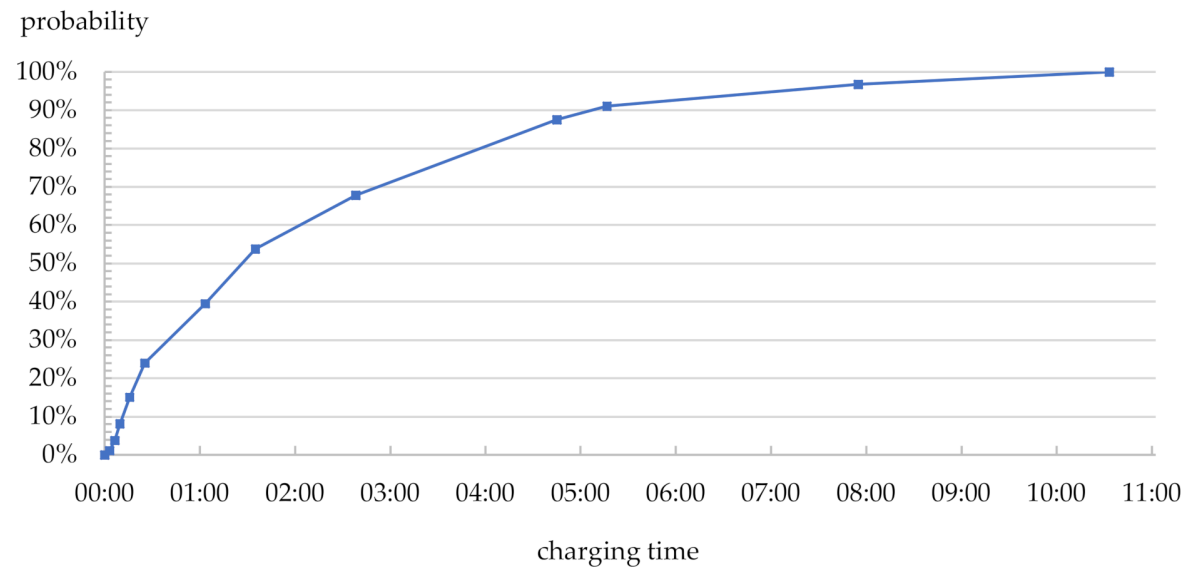

Figure 9. Cumulative distribution function of the resident's EV full charge.

Both the number of guaranteed charging hours $\left(T_{g}\right)$ and the limit that residents must meet to obtain guaranteed charging hours $\left(T_{l}\right)$ were determined based on the time needed to charge by $95 \%$ of the residents.

$$
\begin{gathered}
A F\left(T_{g}\right)=p ; p=95 \% \\
T_{g}=F-1(95) \cong 6 \mathrm{~h} \\
T_{l} \leq X-T_{g} ; X=7 \mathrm{~h}, T_{g}=6 \mathrm{~h} \\
T_{l} \leq 1: 00 \mathrm{AM}
\end{gathered}
$$




\subsection{Technical Aspects of System Dimensioning}

Local transformer station capacity will be first dimensioned to meet the residents' requirements, even though we assume higher utilization of the car park and the entire charging infrastructure by the nonresident group. From the existing series of transformers, it is possible to choose any combination of transformers with different power ratings to ensure the required power output. However, a transformer with an apparent power of $630 \mathrm{kVA}$ is selected for installation in the case study.

The total requirement of recharging 550 resident EVs $\left(Q_{r}\right)$ obtained from the PDF of the daily distance driven by car and average EV consumption corresponds to $5303 \mathrm{kWh}\left(E_{r}\right)$. Within the $12 \mathrm{~h}$ reserved for residents $(Y-X)$, the assumed local transformer with an apparent power of $630 \mathrm{kVA}$ can supply ( $\left.E_{T R_{-} X Y}\right) 7182 \mathrm{kWh}$, and thus fully meets the residents' charging requirements.

$$
\begin{gathered}
P_{n}=S_{n} \cdot \cos \varphi \\
P_{n}=630 \cdot 0.95=598.5 \\
E_{T R_{-} Y X}=P_{n} \cdot(Y-X)[\mathrm{kWh}] \\
E_{T R_{-} Y X}=598.5 \cdot(19-7)=7182[\mathrm{kWh}] \\
E_{T R_{Y X}} \geq E_{r} \\
E_{T R_{Y X}} \geq Q_{r} \cdot P_{C H} \cdot T_{g} \\
3.6 \geq T_{g} \\
c h_{p a r} \leq \frac{P}{P_{C H}} \\
c h_{p a r} \leq \frac{598.5}{3.6} \approx 160
\end{gathered}
$$

Based on the assumed model parameters, each parking place is equipped with a $3.6 \mathrm{~kW} \mathrm{AC}$ single-phase charger. From the load optimization point of view, the car park is divided into three parts. Each is connected to one of the three phases of the transformer. The first and second phases of the transformer are connected with 217 chargers. The third phase then provides power to 216 charging stations. Due to the maximum load of one transformer, it will never charge more than $160 \mathrm{EVs}$ at the same time $\left(c h_{p a r}\right)$. Even though one transformer fully satisfies the requirements for recharging 550 residents, they cannot be guaranteed the required $6 \mathrm{~h}$ of charging. With one transformer, it is possible to guarantee each resident $3.6 \mathrm{~h}$ of charging. However, $3.6 \mathrm{~h}$ of guaranteed charging led to a full charge for only $75 \%$ of residents (Figure 9 ).

Besides, the car park control system, which directs arriving users to the parking places to ensure optimal loading of the entire charging system, helps to optimize even loading of both the transformer stations and their phases.

In the following part of the case study, we will focus on the car park operation in the interval reserved for nonresidents. Their behaviour characterized by charging requirements, arrival times, and parking times is described in the last part of the case study focusing on user' characteristics.

In the case study, we will assume that all nonresidents require both parking and charging of electric cars. Several restrictions are associated with the power of the local transformer station $(P)$, determined based on residents' charging requirements. One of them is the maximum number of chargers used simultaneously $\left(c h_{p a r}\right)$. This is also the reason why it is necessary to postpone some of the nonresidents' charging in very busy intervals (Figure 10). 


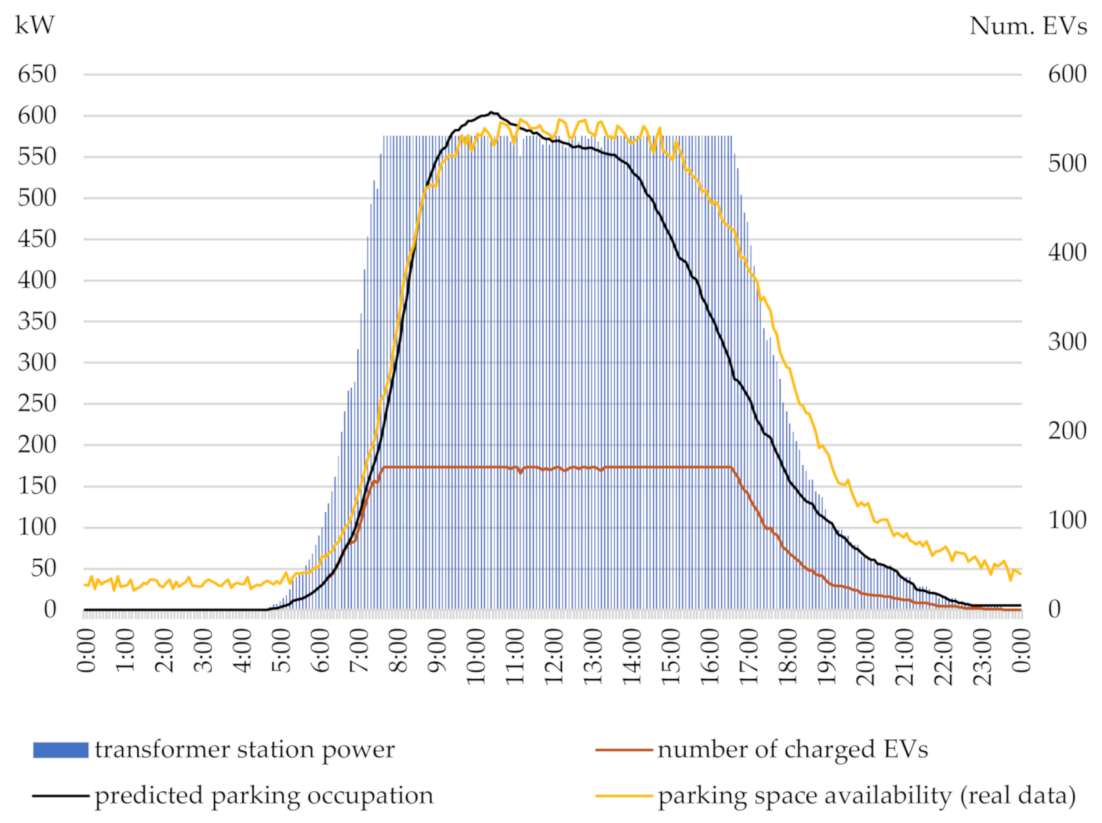

Figure 10. Modelled occupancy in the case of using one transformer.

Nonresidents who have been refused charging wait until one of the previously connected nonresident EVs is fully charged or has finished charging and leaves. The FIFO principle is used for the choice of the next EV for charging from the group of waiting nonresidents, where the longest-waiting nonresident is chosen for charging preferentially (Figure 2).

From the charging point of view, we divide nonresidents into three parts. The first part is composed of nonresidents who were able to recharge throughout the parking time (fully charged). The second part comprises nonresidents whose recharging was shortened due to a shift in the start of charging (partially charged). The third part includes nonresidents whose charging did not start due to a shift in the start of charging (refused).

In the case study, 20 simulations were performed. The number of nonresidents did not change between individual simulations, but their behaviour (charging requirements, arrival times and parking times) did. The results of the simulations showed that on average, $25 \%$ of nonresidents were refused, $15 \%$ were partially charged, and $60 \%$ were fully charged (Figure 11 ). The course of one of the simulations with one transformer is shown in Figure 10, presenting the load of one transformer and the occupancy of the car park compared to the measured real occupancy.

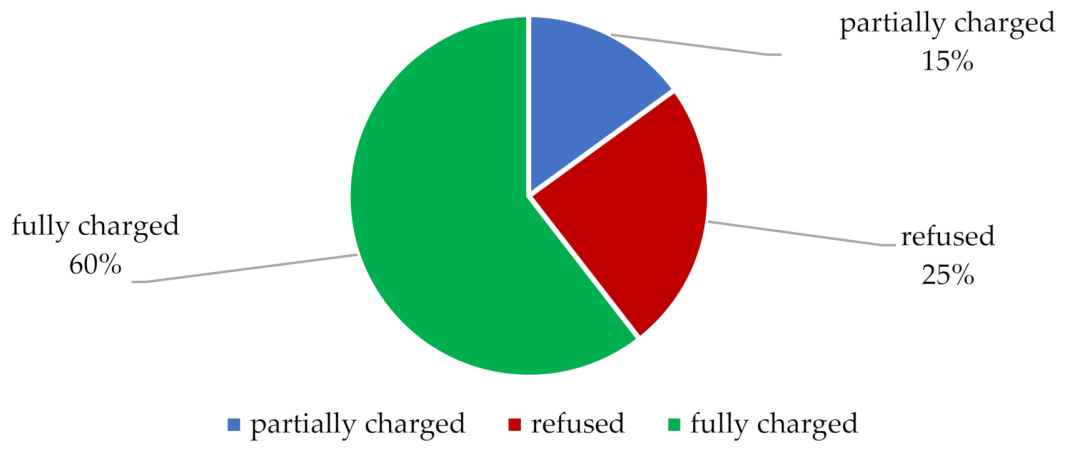

Figure 11. The success of recharging nonresidents in case of using one transformer.

Subsequently, the same set of 20 simulations was performed, but with a difference in the local transformer station power. The existing transformer was supplemented with another one with identical parameters and apparent power in these simulations. This pair of local transformers had a combined 
power of $1197 \mathrm{~kW}$, enabling the simultaneous charging of 320 EVs. The part of nonresidents with refused charging was eliminated due to the increased local transformer station power (Figure 12).

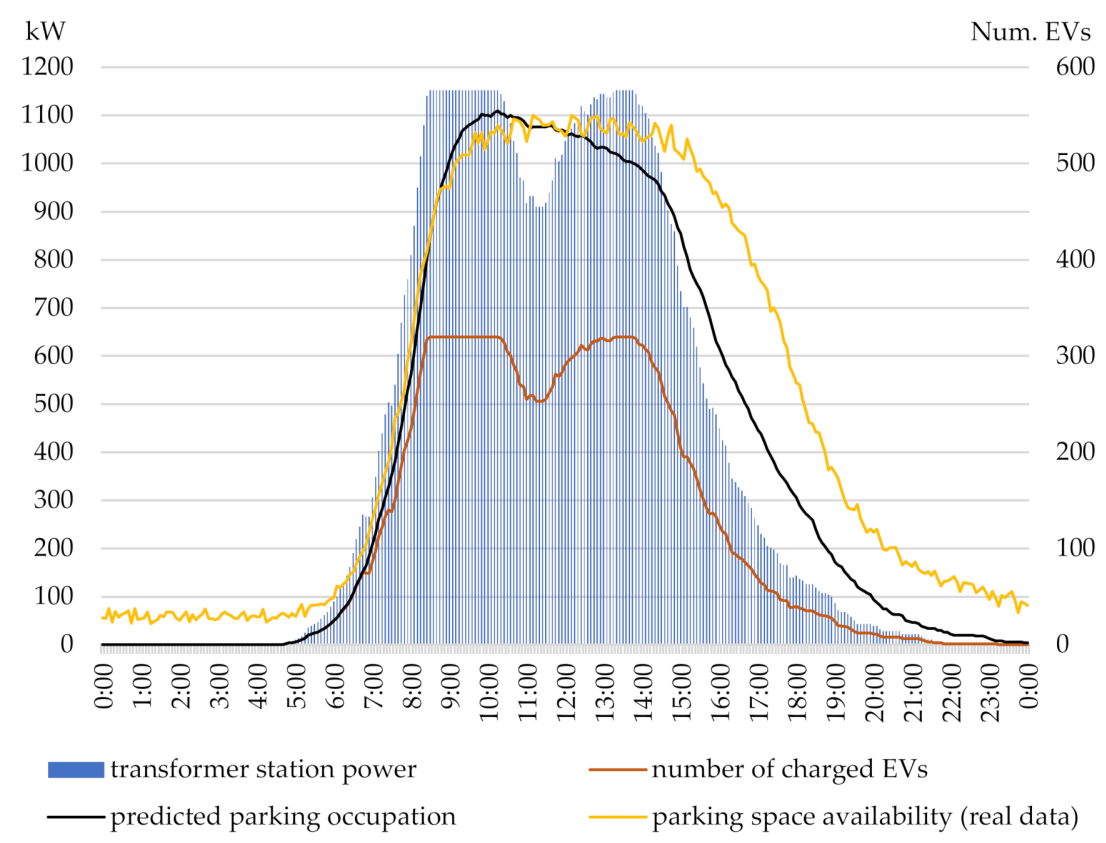

Figure 12. Modelled occupancy in case of using two transformers.

The pair of local transformers reduced the percentage of partially charged nonresidents to $4 \%$ and eliminated the part of nonresidents with refused charging (Figure 13). The course of one of the simulations with two transformers is shown in Figure 12, which presents the load of two transformers and the occupancy of the car park compared to the measured real occupancy.

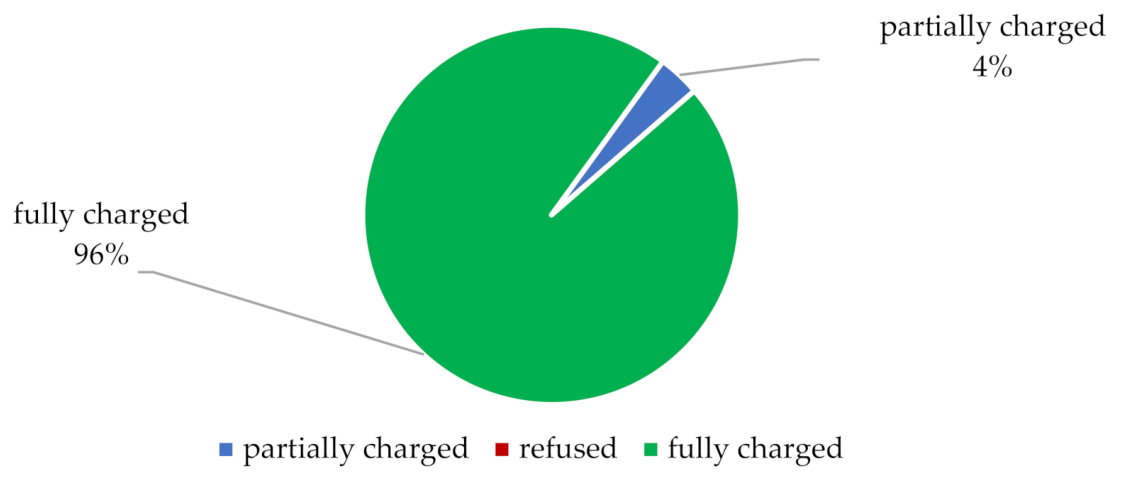

Figure 13. Success of recharging nonresidents in the case of using two transformers.

For the resident group, increasing the output of the local transformer station has the benefit of guaranteeing $6 \mathrm{~h}$ of charging $\left(T_{g}\right)$ and a $95 \%$ success rate of full charging for residents.

\subsection{Economic Analysis of System Dimensioning}

From an economic point of view, it is essential to set the business model parameters so that the costs associated with parking and charging can be competitive with home charging. The key issue is to correctly set the ratio of the CAPEX division between nonresidents and residents. The case study presents the range of recharging costs depending on how CAPEX are distributed among users (Table 1). 
Table 1. Investment costs.

\begin{tabular}{|c|c|c|c|c|c|c|c|}
\hline & TLT & $q$ & Unit Price & $\begin{array}{c}\text { Total Costs } \\
\text { of } 1 \text { TS }\end{array}$ & $\begin{array}{c}\text { Costs of } \\
\text { Additional TS }\end{array}$ & $\begin{array}{l}\text { Annuity } \\
\text { for } 1 \text { TS }\end{array}$ & $\begin{array}{c}\text { Annuity for } \\
\text { Additional TS }\end{array}$ \\
\hline & Year & - & EUR & EUR & EUR & EUR & EUR \\
\hline Disconnector and isolator & 35 & 1 & 566 & 566 & 566 & 142 & 142 \\
\hline Circuit breaker BH400 & 35 & 1 & 453 & 453 & 453 & 113 & 113 \\
\hline Fuses PM45 16A & 35 & 3 & 74 & 221 & 221 & 55 & 55 \\
\hline Pipes for cooling & 35 & 1 & 302 & 302 & 302 & 75 & 75 \\
\hline Installation material & 35 & 1 & 377 & 377 & 377 & 94 & 94 \\
\hline Charging control system & 35 & 1 & 37,736 & 37,736 & 0 & 9438 & 0 \\
\hline Charging station & 10 & 650 & 755 & 490,566 & 0 & 137,394 & 0 \\
\hline Connection fee & 35 & 1 & 6038 & 6038 & 6038 & 1510 & 1510 \\
\hline
\end{tabular}

Exchange rate: $1 \mathrm{EUR}=26.5 \mathrm{CZK}$.

The costs associated with electricity consumption (OPEX) are slightly different across countries. Since the car park is located in the Czech Republic, the price of electricity consists of a fixed and a variable part. The fixed part includes the fee for reserved power, renewable energy sources (RES) and the market operator, while the variable part, depending on electricity consumed, includes the price of energy, distribution services, system services and the electricity tax. The modelled annual electricity consumption and actual prices are shown in Table 2.

Table 2. Annual electricity bill [37,38].

\begin{tabular}{ccccc}
\hline & Unit & Unit Costs (Incl. VAT) & Total Annual Costs & Additional TS Annuity Costs \\
\hline Energy & EUR/MWh & 75.34 & 169,944 & - \\
Distribution services & EUR/MWh & 3.37 & 7604 & - \\
Reserved power & EUR/MW/month & 3856 & 27,762 & 27,762 \\
System services & EUR/MWh & 3.52 & 7943 & - \\
RES fee & EUR/MW/month & 2633 & 18,961 & 18,961 \\
Electricity tax & EUR/MWh & 1.29 & 2915 & - \\
Market operator fee & EUR/month & 0.23 & 0.23 & - \\
Additional sale 2nd TS & EUR/MWh & 83.52 & - & 54,800 \\
\hline
\end{tabular}

TS = transformer station; VAT $=$ value added tax $21 \%$; exchange rate: $1 \mathrm{EUR}=26.5 \mathrm{CZK}$.

Table 3 shows the fixed operating costs related to transformer maintenance and overhauls and the annual energy losses incurred.

Table 3. Fixed operating costs.

\begin{tabular}{cccc}
\hline & Costs Incl. VAT [EUR] & Annualized Costs [EUR] & Additional TS Annual Costs [EUR] \\
\hline Annual inspection & 457 & 457 & 457 \\
Major inspection every five years & 2283 & 849 & 849 \\
Annual energy losses in TS (WL) & 732 & 732 & 732 \\
Annual calibration of chargers & 4566 & 4566 & - \\
\hline
\end{tabular}

TS = transformer station; VAT = value added tax 21\%; exchange rate: $1 \mathrm{EUR}=26.5 \mathrm{CZK}$.

Since the transformer station causes most losses, the empirical formula given by CSN 341610 standard is used for the estimation of annual losses in the transformer station:

$$
\begin{gathered}
T_{L}=\left[0.2 \frac{T_{m}}{T_{0}}+0.8\left(\frac{T_{m}}{T_{0}}\right)^{2}\right] \cdot T_{0}=\left[0.2 \frac{1958}{8760}+0.8\left(\frac{1958}{8760}\right)^{2}\right] \cdot 8760=741[\text { hours }] \\
W_{L}=P_{n l} T_{o}+P_{k n} \frac{S_{m}^{2}}{S_{n}^{2}} T_{L}=0.6 \cdot 8760+6.5 \cdot \frac{606^{2}}{630^{2}} \cdot 741=9721[\mathrm{kWh}]
\end{gathered}
$$

Although the technical part shows that one transformer provides sufficient power for residents but only with a $75 \%$ success rate of full charging for residents, the percentage of refused nonresidents creates 
significant NCFC. Therefore, the previous tables also contain additional annualized costs of deploying one more transformer. The sum of these annualized costs indicates whether it is advantageous to deploy a second transformer. The economic part aims to determine the levelized costs of electricity (LCOE) for both the nonresident and resident groups.

$$
L C O E=\frac{N_{i}+\sum_{t=1}^{n}\left(M_{t}+N_{E t}\right)(1+r)^{-t}}{\sum_{t=1}^{n} E_{t}(1+r)^{-t}} \approx \frac{C_{A}+M+F_{t}}{E_{A}}
$$

Here, the variable $N_{i}$ denotes the initial investment in the equipment; $M$ denotes the annual maintenance expenditures, and $N_{E}$ is the electricity bill in the year $t$. Providing that the values are not changed year-on-year, the variables $C_{A}$ and $F_{t}$ can be set. $C_{A}$ indicates the annualized costs for the corresponding discount rate $r$, and $F_{t}$ denotes the annual electricity bill. $E$ represents annual electricity sold $(\mathrm{kWh})$.

\section{Results}

The following chapter presents the results of the model applied to real data obtained from the Letňany car park, Prague, and the users' charging needs from the ŠKO-ENERGO charging station data. The values of levelized costs of electricity showing the competitiveness of charging points are presented.

\subsection{LCOE of Charging Tariff Rate}

As the LCOE are mainly dependent on the discount rate and the fixed operating cost ratio, the following results show minimum user tariff rate dependence. Furthermore, the tables contain additional thresholds for the investor's more qualified decision.

The initial decision regarding construction of a charging point is to plan the installed capacity of the transformer station. Figure 14 shows the share of uncovered costs caused by the nonresidents with respect to the annualized costs of an additional transformer.

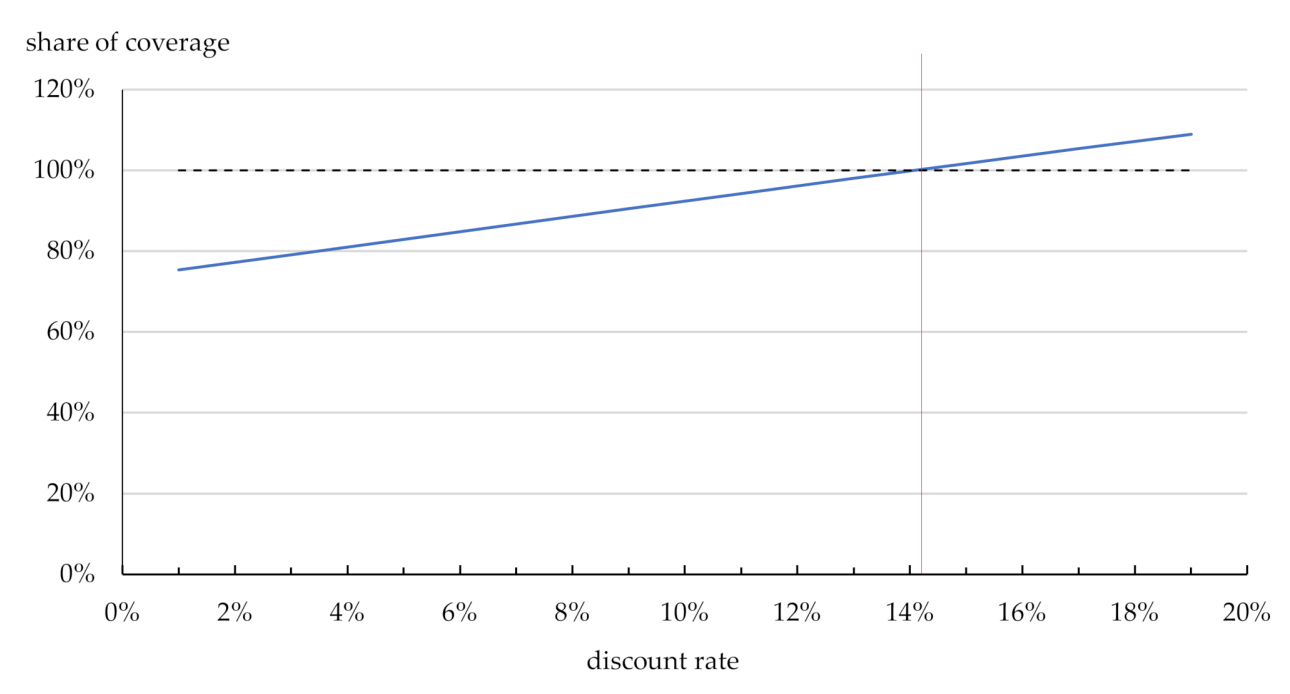

Figure 14. Share of coverage of annualized costs of additional TS.

The first threshold is marked in Figure 14. The share of coverage of annualized costs of additional TS is marked with the red line and is the boundary for the decision to increase the installed capacity of transformers. It follows from the results of the case study that an additional transformer for a discount rate higher than $15 \%$ should be installed. This boundary is also shown in Tables 4 and 5 . 
Table 4. Dependence of residential LCOE on discount rate and on share of inclusion of fixed costs in residential price in case two TS are installed.

\begin{tabular}{|c|c|c|c|c|c|c|c|c|c|c|c|c|c|c|c|}
\hline \multirow{12}{*}{ 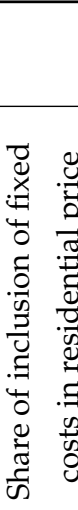 } & \multicolumn{15}{|c|}{ Discount Rate } \\
\hline & $\%$ & 5 & 7 & 9 & 11 & 13 & 15 & 17 & 19 & 21 & 23 & 25 & 27 & 29 & 31 \\
\hline & 0 & $0.08^{1}$ & $0.08^{1}$ & $0.08^{1}$ & $0.08^{1}$ & $0.08^{1}$ & 0.08 & 0.08 & 0.08 & 0.08 & 0.08 & 0.08 & 0.08 & 0.08 & 0.08 \\
\hline & 10 & $0.09^{1}$ & $0.09^{1}$ & $0.09^{1}$ & $0.09^{1}$ & $0.09^{1}$ & 0.10 & 0.10 & 0.10 & 0.10 & 0.10 & 0.10 & 0.10 & 0.10 & 0.10 \\
\hline & 20 & $0.10^{1}$ & $0.10^{1}$ & $0.10^{1}$ & $0.10^{1}$ & $0.11^{1}$ & 0.11 & 0.11 & 0.11 & 0.11 & 0.11 & 0.11 & 0.11 & 0.11 & 0.12 \\
\hline & 30 & $0.11^{1}$ & $0.11^{1}$ & $0.11^{1}$ & $0.11^{1}$ & $0.12^{1}$ & 0.12 & 0.12 & 0.12 & 0.12 & 0.12 & 0.13 & 0.13 & 0.13 & 0.13 \\
\hline & 40 & $0.12^{1}$ & $0.12^{1}$ & $0.12^{1}$ & $0.13^{1}$ & $0.13^{1}$ & 0.13 & 0.13 & 0.13 & 0.14 & 0.14 & 0.14 & 0.14 & 0.15 & 0.15 \\
\hline & 50 & $0.13^{1}$ & $0.13^{1}$ & $0.13^{1}$ & $0.14^{1}$ & $0.14^{1}$ & 0.14 & 0.14 & 0.15 & 0.15 & 0.15 & 0.16 & 0.16 & 0.16 & 0.16 \\
\hline & 60 & $0.14^{1}$ & $0.14^{1}$ & $0.14^{1}$ & $0.15^{1}$ & $0.15^{1}$ & 0.15 & 0.16 & 0.16 & 0.16 & 0.17 & 0.17 & 0.17 & 0.18 & 0.18 \\
\hline & 70 & $0.15^{1}$ & $0.15^{1}$ & $0.15^{1}$ & $0.16^{1}$ & $0.16^{1}$ & 0.16 & 0.17 & 0.17 & 0.18 & 0.18 & 0.18 & $0.19^{2}$ & $0.19^{2}$ & $0.20^{2}$ \\
\hline & 80 & $0.16^{1}$ & $0.16^{1}$ & $0.16^{1}$ & $0.17^{1}$ & $0.17^{1}$ & 0.18 & 0.18 & 0.18 & $0.19^{2}$ & $0.19^{2}$ & $0.20^{2}$ & $0.20^{2}$ & $0.21^{2}$ & $0.21^{3}$ \\
\hline & 90 & $0.16^{1}$ & $0.17^{1}$ & $0.17^{1}$ & $0.18^{1}$ & $0.18^{1}$ & $0.19^{2}$ & $0.19^{2}$ & $0.20^{2}$ & $0.20^{2}$ & $0.21^{2}$ & $0.21^{2}$ & $0.22^{3}$ & $0.22^{3}$ & $0.23^{3}$ \\
\hline & 100 & $0.17^{1}$ & $0.18^{1}$ & $0.18^{1}$ & $0.19^{1}$ & $0.19^{1}$ & $0.20^{2}$ & $0.20^{2}$ & $0.21^{2}$ & $0.22^{2}$ & $0.22^{3}$ & $0.23^{3}$ & $0.23^{3}$ & $0.24^{3}$ & $0.25^{3}$ \\
\hline
\end{tabular}

Table 5. Dependence of nonresidential LCOE on discount rate and on share of inclusion of fixed costs in residential price in case two TS are installed.

\begin{tabular}{|c|c|c|c|c|c|c|c|c|c|c|c|c|c|c|c|}
\hline \multirow{13}{*}{ 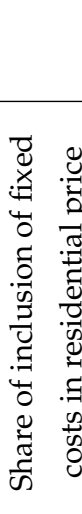 } & \multicolumn{15}{|c|}{ Discount Rate } \\
\hline & $\%$ & 5 & 7 & 9 & 11 & 13 & 15 & 17 & 19 & 21 & 23 & 25 & 27 & 29 & 31 \\
\hline & 0 & $0.14^{1}$ & $0.14^{1}$ & $0.15^{1}$ & $0.15^{1}$ & $0.15^{1}$ & 0.16 & 0.16 & 0.17 & 0.17 & 0.17 & 0.18 & 0.18 & $0.19^{3}$ & 0.19 \\
\hline & 10 & $0.14^{1}$ & $0.14^{1}$ & $0.14^{1}$ & $0.14^{1}$ & $0.15^{1}$ & 0.15 & 0.15 & 0.16 & 0.16 & 0.16 & 0.17 & 0.17 & 0.18 & 0.18 \\
\hline & 20 & $0.13^{1}$ & $0.13^{1}$ & $0.14^{1}$ & $0.14^{1}$ & $0.14^{1}$ & 0.14 & 0.15 & 0.15 & 0.15 & 0.16 & 0.16 & 0.16 & 0.17 & 0.17 \\
\hline & 30 & $0.12^{1}$ & $0.13^{1}$ & $0.13^{1}$ & $0.13^{1}$ & $0.13^{1}$ & 0.14 & 0.14 & 0.14 & 0.14 & 0.15 & 0.15 & 0.15 & 0.16 & 0.16 \\
\hline & 40 & $0.12^{1}$ & $0.12^{1}$ & $0.12^{1}$ & $0.12^{1}$ & $0.13^{1}$ & 0.13 & 0.13 & 0.13 & 0.14 & 0.14 & 0.14 & 0.14 & 0.14 & 0.15 \\
\hline & 50 & $0.11^{1}$ & $0.11^{1}$ & $0.12^{1}$ & $0.12^{1}$ & $0.12^{1}$ & 0.12 & 0.12 & 0.12 & 0.13 & 0.13 & 0.13 & 0.13 & 0.13 & 0.14 \\
\hline & 60 & $0.11^{1}$ & $0.11^{1}$ & $0.11^{1}$ & $0.11^{1}$ & $0.11^{1}$ & 0.11 & 0.11 & 0.12 & 0.12 & 0.12 & 0.12 & 0.12 & 0.12 & 0.13 \\
\hline & 70 & $0.10^{1}$ & $0.10^{1}$ & $0.10^{1}$ & $0.10^{1}$ & $0.10^{1}$ & 0.11 & 0.11 & 0.11 & 0.11 & 0.11 & 0.11 & 0.11 & 0.11 & 0.12 \\
\hline & 80 & $0.10^{1}$ & $0.10^{1}$ & $0.10^{1}$ & $0.10^{1}$ & $0.10^{1}$ & 0.10 & 0.10 & 0.10 & 0.10 & 0.10 & 0.10 & 0.10 & 0.10 & 0.10 \\
\hline & 90 & $0.09^{1}$ & $0.09^{1}$ & $0.09^{1}$ & $0.09^{1}$ & $0.09^{1}$ & 0.09 & 0.09 & 0.09 & 0.09 & 0.09 & 0.09 & 0.09 & 0.09 & 0.09 \\
\hline & 100 & $0.08^{1}$ & $0.08^{1}$ & $0.08^{1}$ & $0.08^{1}$ & $0.08^{1}$ & 0.08 & 0.08 & 0.08 & 0.08 & 0.08 & 0.08 & 0.08 & 0.08 & 0.08 \\
\hline
\end{tabular}

${ }^{1}$ One TS is sufficient; ${ }^{3}$ one TS, price exceeds $0.19 \mathrm{EUR} / \mathrm{kWh}$. 
Both tables show the LCOE value according to Equation (33) for the case of installation of two transformers. For a discount rate lower than $15 \%$, it is profitable to install one transformer only. For the case of one transformer, the values highlighted in yellow are replaced with the LCOE values.

The table also shows the monetary limits per $\mathrm{kWh}$ depending on the number of installed transformer stations. The rate of $0.19 \mathrm{EUR} / \mathrm{kWh}$ was chosen as a reference value, which corresponds to the price of home charging. The red area indicates the monetary limits in the case of installation of one transformer. On the contrary, the green area indicates the same limit for installation of two.

\subsection{Setting of Minimum Blocking Tariff Rate}

If we accept that users in one group can exceed the parking time and thus block others in the other group, then the size of the NCFC is based on the LCOE of the opposite group of users. The following tables (Tables 6 and 7) show the amount of NCFC depending on the discount rate and the share of fixed costs included in the price according to Equations (2) and (4).

Table 6. Nonresident blocking tariff rate in EUR/night.

\begin{tabular}{|c|c|c|c|c|c|c|c|c|c|c|c|c|c|c|c|}
\hline & \multicolumn{15}{|c|}{ Discount Rate } \\
\hline \multirow{12}{*}{ 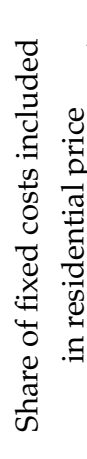 } & $\%$ & 5 & 7 & 9 & 11 & 13 & 15 & 17 & 19 & 21 & 23 & 25 & 27 & 29 & 31 \\
\hline & 0 & 0.0 & 0.0 & 0.0 & 0.0 & 0.0 & 0.0 & 0.0 & 0.0 & 0.0 & 0.0 & 0.0 & 0.0 & 0.0 & 0.0 \\
\hline & 10 & 0.4 & 0.4 & 0.4 & 0.4 & 0.4 & 0.5 & 0.5 & 0.5 & 0.5 & 0.5 & 0.6 & 0.6 & 0.6 & 0.6 \\
\hline & 20 & 0.7 & 0.7 & 0.8 & 0.8 & 0.9 & 0.9 & 1.0 & 1.0 & 1.0 & 1.1 & 1.1 & 1.2 & 1.2 & 1.3 \\
\hline & 30 & 1.1 & 1.1 & 1.2 & 1.2 & 1.3 & 1.4 & 1.4 & 1.5 & 1.6 & 1.6 & 1.7 & 1.8 & 1.9 & 1.9 \\
\hline & 40 & 1.4 & 1.5 & 1.6 & 1.7 & 1.7 & 1.8 & 1.9 & 2.0 & 2.1 & 2.2 & 2.3 & 2.4 & 2.5 & 2.6 \\
\hline & 50 & 1.8 & 1.9 & 2.0 & 2.1 & 2.2 & 2.3 & 2.4 & 2.5 & 2.6 & 2.7 & 2.8 & 3.0 & 3.1 & 3.2 \\
\hline & 60 & 2.1 & 2.2 & 2.4 & 2.5 & 2.6 & 2.7 & 2.9 & 3.0 & 3.1 & 3.3 & 3.4 & 3.6 & 3.7 & 3.9 \\
\hline & 70 & 2.5 & 2.6 & 2.7 & 2.9 & 3.0 & 3.2 & 3.3 & 3.5 & 3.7 & 3.8 & 4.0 & 4.2 & 4.3 & 4.5 \\
\hline & 80 & 2.8 & 3.0 & 3.1 & 3.3 & 3.5 & 3.6 & 3.8 & 4.0 & 4.2 & 4.4 & 4.6 & 4.7 & 4.9 & 5.1 \\
\hline & 90 & 3.2 & 3.4 & 3.5 & 3.7 & 3.9 & 4.1 & 4.3 & 4.5 & 4.7 & 4.9 & 5.1 & 5.3 & 5.6 & 5.8 \\
\hline & 100 & 3.5 & 3.7 & 3.9 & 4.1 & 4.3 & 4.6 & 4.8 & 5.0 & 5.2 & 5.5 & 5.7 & 5.9 & 6.2 & 6.4 \\
\hline
\end{tabular}

Table 7. Resident blocking tariff rate in EUR/day.

\begin{tabular}{|c|c|c|c|c|c|c|c|c|c|c|c|c|c|c|c|}
\hline & \multicolumn{15}{|c|}{ Discount Rate } \\
\hline \multirow{12}{*}{ 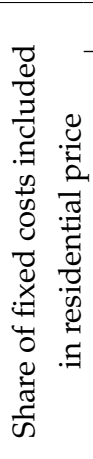 } & $\%$ & 5 & 7 & 9 & 11 & 13 & 15 & 17 & 19 & 21 & 23 & 25 & 27 & 29 & 31 \\
\hline & 0 & 0.9 & 1.0 & 1.0 & 1.1 & 1.1 & 1.2 & 1.3 & 1.3 & 1.4 & 1.4 & 1.5 & 1.6 & 1.6 & 1.7 \\
\hline & 10 & 0.8 & 0.9 & 0.9 & 1.0 & 1.0 & 1.1 & 1.1 & 1.2 & 1.2 & 1.3 & 1.4 & 1.4 & 1.5 & 1.5 \\
\hline & 20 & 0.7 & 0.8 & 0.8 & 0.9 & 0.9 & 1.0 & 1.0 & 1.1 & 1.1 & 1.2 & 1.2 & 1.3 & 1.3 & 1.4 \\
\hline & 30 & 0.7 & 0.7 & 0.7 & 0.8 & 0.8 & 0.8 & 0.9 & 0.9 & 1.0 & 1.0 & 1.1 & 1.1 & 1.1 & 1.2 \\
\hline & 40 & 0.6 & 0.6 & 0.6 & 0.7 & 0.7 & 0.7 & 0.8 & 0.8 & 0.8 & 0.9 & 0.9 & 0.9 & 1.0 & 1.0 \\
\hline & 50 & 0.5 & 0.5 & 0.5 & 0.5 & 0.6 & 0.6 & 0.6 & 0.7 & 0.7 & 0.7 & 0.8 & 0.8 & 0.8 & 0.9 \\
\hline & 60 & 0.4 & 0.4 & 0.4 & 0.4 & 0.5 & 0.5 & 0.5 & 0.5 & 0.6 & 0.6 & 0.6 & 0.6 & 0.7 & 0.7 \\
\hline & 70 & 0.3 & 0.3 & 0.3 & 0.3 & 0.3 & 0.4 & 0.4 & 0.4 & 0.4 & 0.4 & 0.5 & 0.5 & 0.5 & 0.5 \\
\hline & 80 & 0.2 & 0.2 & 0.2 & 0.2 & 0.2 & 0.2 & 0.3 & 0.3 & 0.3 & 0.3 & 0.3 & 0.3 & 0.3 & 0.3 \\
\hline & 90 & 0.1 & 0.1 & 0.1 & 0.1 & 0.1 & 0.1 & 0.1 & 0.1 & 0.1 & 0.1 & 0.2 & 0.2 & 0.2 & 0.2 \\
\hline & 100 & 0.0 & 0.0 & 0.0 & 0.0 & 0.0 & 0.0 & 0.0 & 0.0 & 0.0 & 0.0 & 0.0 & 0.0 & 0.0 & 0.0 \\
\hline
\end{tabular}

\section{Discussion}

The data analysis obtained from real chargers shows some important information: Users leave their EVs parked and connected to the charger for a longer time than is necessary for recharging the battery. A shorter charging time would be sufficient for almost $90 \%$ of the $330 \mathrm{EV}$ user sample to charge fully. Users could even use a $3.6 \mathrm{~kW}$ AC charger to achieve the same recharging level in the same amount of parking time.

These results also correlate with the studies $[4,6]$ focusing on the average daily distance users travel by car. The average daily distance travelled by a user varies between $48 \mathrm{~km}$ and $50 \mathrm{~km}$, and this range also corresponds to the charging requirements in our analysis. 
Therefore, in terms of the development of the charging station installation, a sufficient number of chargers is a priority in urban and suburban areas rather than the construction of fewer chargers with higher charging power. The same consideration must be applied when charging infrastructure is built in a P + R car park. Due to the long parking in the daytime, this type of car park is a suitable candidate for constructing a sufficient number of low-power chargers in an urban area.

Our model shows that equipping a car park with chargers is a simple way to increase parking place efficiency. Due to the high occupancy during the daytime and the low occupancy overnight, $\mathrm{P}+\mathrm{R}$ car parks have a great potential for increasing by installing chargers and introducing a night reservation system. In addition, the evening/night reservation ensures a sufficient number of parking places for $\mathrm{EV}$ owners living close to the $\mathrm{P}+\mathrm{R}$ car park but having no parking place or garage.

The reservation provides user comfort and ensures charging of the EV for the next day comparable to owners of private garages or parking places. By comparison, home charging in the Czech Republic ensures EV owners to use the special electricity tariff D27d [39]. This tariff provides eight-hour charging in the interval from $6 \mathrm{pm}$ to $8 \mathrm{am}$ with a price per $\mathrm{kWh}$ approaching 0.08 EUR.

As shown in the economic part of the case study, our solution offers a twelve-hour charging span for a constant price between 0.09 and 0.21 EUR per $\mathrm{kWh}$. This price depends on the discount rate and percentage distribution of non-covered costs between the resident and nonresident groups.

The proposed solution increases the efficiency of existing parking places situated in urban areas, where car parks are usually insufficient. Furthermore, the proposed solution does not dissuade potential new EV owners having no private parking from the purchase of a new EV. Thus, the development of electromobility is significantly supported.

Based on the case study results, the dimensioning of local transformer station power is more in accordance with the EV charging requirements of users arriving during the daytime (nonresidents). Insufficiently dimensioned local transformer station power and the need for simultaneous use of a smaller number of chargers result in financial losses.

The threshold for investors to increase the power of the local transformer station is set by comparing the annualized costs of an additional transformer and total non-covered costs from unsold electricity. Under the conditions described in the case study for a discount rate higher than $15 \%$, the non-covered costs exceed the annualized costs of increasing the local transformer station power. In such cases, the investment in the additional transformer is profitable.

Increasing the power of the local transformer station is beneficial not only for nonresidents, whose percentage of refusal is reduced, but also for the residents, whose guaranteed charging hours may be prolonged. Therefore, doubled installed power allows simultaneous charging of a larger number of EVs, and guarantees up to twice the number of charging hours $(\mathrm{Tg})$.

The model considers installation of oil-immersed transformers, which, unlike the dry type, require a higher degree of fire safety and measures against possible oil leakage. However, if we take into account the same price category, their advantages prevail. Compared to the dry type, the oil-immersed transformer achieves both lower short-circuiting, lower no-load loss and lower noise, guarantees thermal stability during operation at higher loads, and offers the possibility of continuous operation at the rated load [40]. We assume that installing this type of transformer near the $\mathrm{P}+\mathrm{R}$ car park will meet all the requirements defined by the fire safety standard.

It is evident that an analysis of the behaviour and requirements of specific EV users both living near the site and often using the daytime parking services will be required to achieve a better setting of the parameters of the whole model. A limiting factor of the input data is that they describe only the car park occupancy, losing the information about arrivals and departures within the measured five-minute interval. However, the occupancy data used have been adjusted for public holidays and vacations. Still, it is unknown whether these values may have been affected by, e.g., cultural events which tend to be organized near the car park during the year. 


\section{Conclusions}

The paper analyses the technical and economic potential of installing low-power chargers in an existing car park. The assumed model of a car park equipped with chargers offers a solution to one of the most common obstacles of potential EV users when they decide whether to buy an electric car: the absence of a private charging place. Furthermore, the model solves the problem of the lack of chargers in densely populated districts by installing the charging stations in an existing car park.

Generally, the model defines two groups of users. The first group (nonresidents) are users arriving randomly in the daytime who commute to the site for work or other purposes. Nonresidents usually leave cars parked there for a longer time. The second group (residents) live close to the car park and rent parking places primarily for overnight charging.

However, the major difference between the resident and nonresident groups is that nonresident users' priority is parking rather than charging. The nonresidents' EVs are charged if the current load of the transformer station makes this possible. Contrarily, the resident users' priority is the guaranteed charging. The model is based on real user parking behaviour, which then complements the requirements for recharging. The modelling results are the percentage of satisfaction of individual groups (especially nonresidents) under specifically selected charging infrastructure parameters.

The case study in the paper uses recharging data from the company ŠKO-ENERGO and parking place occupancy data for a P $+\mathrm{R}$ car park in Prague Letňany. The charging data contain three months of testing data from the year 2020, 330 charging iterations in total from seven charging points. All charging points were equipped with $22 \mathrm{~kW}$ DC power chargers, four of which could also charge with $50 \mathrm{~kW} \mathrm{DC}$. The parking occupancy data describe the car park, with a capacity of 650 parking places, in five-minute intervals from the 1st quarter of 2013 to the 4 th quarter of 2016. The charging analysis shows that users left the EVs parked and connected to the charger for a longer time than required to recharge the battery. Comparing charging and time spent at the charger, almost $90 \%$ of the tested EV users would have done with a shorter charging time to recharge the required energy. They could even use a $3.6 \mathrm{~kW} \mathrm{AC}$ charger to achieve the same recharging level in the same amount of parking time.

Knowing the above information, the model designs the optimal size of charging equipment. By creating a reservation system for residents, the LCOE of nonresident charging at a discount rate of $15 \%$ will drop from around 0.15 EUR to 0.11 EUR, which competes with the price of other types of public charging. The simulation results show that although the model uses low-power chargers with an output of $3.6 \mathrm{~kW}$, the daytime parking time in the $\mathrm{P}+\mathrm{R}$ car park studied is sufficient to fully charge to $96 \%$ for nonresidents. However, in order to guarantee $6 \mathrm{~h}$ of resident charging and thus achieve a $95 \%$ success rate of full charging, it is necessary to add another transformer to the local transformer station.

Another benefit of the presented solution, in addition to more efficient use of parking places, is ensuring the stability of the electric grid during the charging of a large number of EVs in one place by dividing the power between them. Dividing the power between randomly placed charging stations of different owners within the power grid would not be as easy as dividing the power within the charging stations in one car park. In the case of demand for charging a group of electric vehicles concentrated in one place, the local power grid would be significantly overloaded. Then, it is possible to support the overall stability of the local power grid with battery storage, which would smooth out peaks in the load.

Author Contributions: All authors contributed to the research in the paper. L.D. and M.H. conceived and designed the model; L.D., M.H., M.V. and J.K. provided the data; L.D., M.H. and J.K. analysed the data; L.D. wrote the paper. All authors have read and agreed to the published version of the manuscript.

Funding: This work is supported by the Student Grant Competition of CTU (Grant No. SGS20/125/OHK5/2T/13 and Grant No. SGS20/126/OHK5/2T/13).

Acknowledgments: Above all, we would like to thank the reviewers and ŠKO-ENERGO. We thank the anonymous reviewers for their careful work and ŠKO-ENERGO for providing anonymized data from the operation of their charging stations. 
Conflicts of Interest: The authors declare no conflict of interest.

\section{Abbreviations}

$\begin{array}{ll}\text { CAPEX } & \text { Capital expenditures } \\ \text { CDF } & \text { Cumulative distribution function } \\ \text { DSM } & \text { Demand side management } \\ \text { EV } & \text { Electric vehicle } \\ \text { HV } & \text { High voltage } \\ \text { LCOE } & \text { Levelized costs of electricity } \\ \text { LV } & \text { Low voltage } \\ \text { NCFC } & \text { Non-covered fixed costs } \\ \text { OPEX } & \text { Operating expenditures } \\ \text { P2P } & \text { Peer-to-peer } \\ \text { PDF } & \text { Probability density function } \\ \text { P }+ \text { R } & \text { Park and ride car park } \\ \text { RES } & \text { Renewable energy sources } \\ \text { TS } & \text { Transformer station }\end{array}$

\section{Variables}

$\hat{A}$

E

$E_{r}$

$E_{r}(x)$

$E_{T R \_Y X}$

$c h_{\text {par }}$

$L$

LCOE

$L_{p \_k W h}$

$M$

$N_{E}$

$N_{i}$

$N_{\text {var }}$

$N_{w}$

$P$

$P_{\mathrm{CH}}$

Ph_par

$P_{k n}$

$P_{n}$

$P_{n l}$

$q$

$Q$

$Q_{p l}$

$Q_{r}$

R

$r$

$S_{m}$

$S_{n}$

$t$

$T_{0}$

Vector with distribution of arrivals of nonresidents in five minutes during the day

Electricity sold per year [kWh]

Total resident recharging requirement $[\mathrm{kWh}]$

Recharging requirement of resident $x[\mathrm{kWh}]$

Energy that can be provided in interval from $\mathrm{Y}$ to $\mathrm{X}$ by local transformer [kWh]

Maximum number of chargers used simultaneously

Length of nonresidential stay [h]

Levelized costs of electricity

Non-covered fixed costs for unsold kilowatt hours [EUR]

Annual maintenance expenditures [EUR]

Electricity bill in year $\mathrm{t}$ [EUR]

Initial investment in equipment [EUR]

Unit price per $\mathrm{kWh}$ [EUR]

Number of EVs waiting to start recharging

Transformer station output power [kW]

Power of one charger [kW]

Power consumption of all chargers used simultaneously $\mathrm{ch}_{\mathrm{par}}$. [kW]

Short-circuit transformer losses [kW]

TS output power $[\mathrm{kW}]$

Power transformer no-load loss [kW]

Quantity

Number of parking places occupied at weekends

Number of parking places in car park

Parking places reserved for residents

Tariff rate for exceeding the parking time [EUR]

Discount rate [\%]

Maximum apparent-power load of transformer [kVA]

Apparent power of transformer station [kVA]

Time step

Annual operating time of transformer station [h] 
$T_{g} \quad$ Guaranteed charging time for residents [h]

$T_{l} \quad$ Last morning hour of guaranteed $\mathrm{h}$

$T_{L} \quad$ Time equivalent of losses at maximum transformer load per year [h]

$T_{L T} \quad$ Lifetime [years]

$T_{m} \quad$ Utility factor [h]

$T_{0} \quad$ Average daily use of one charging station [h]

$T_{r}(x) \quad$ Charging time of $\mathrm{x}$-th resident [h]

$T_{w}(x) \quad$ Waiting time in queue

$W_{L} \quad$ Annual energy losses in transformer

$X \quad$ End of interval reserved for residents

$Y \quad$ Beginning of interval reserved for residents

\section{References}

1. Xiao, H.; Xu, M.; Yang, H. Pricing strategies for shared parking management with double auction approach: Differential price vs. uniform price. Transp. Res. Part. E Logist. Transp. Rev. 2020, 136, 101899. [CrossRef]

2. Plenter, F.; Chasin, F.; Von Hoffen, M.; Betzing, J.H.; Betzing, J.H.; Becker, J. Assessment of peer-provider potentials to share private electric vehicle charging stations. Transp. Res. Part. D Transp. Environ. 2018, 64, 178-191. [CrossRef]

3. Kester, J.; Noel, L.; De Rubens, G.Z.; Sovacool, B.K. Policy mechanisms to accelerate electric vehicle adoption: A qualitative review from the Nordic region. Renew. Sustain. Energy Rev. 2018, 94, 719-731. [CrossRef]

4. Zhao, Z.; Zhang, L.; Yang, M.; Chai, J.; Li, S. Pricing for private charging pile sharing considering EV consumers based on non-cooperative game model. J. Clean. Prod. 2020, 254, 120039. [CrossRef]

5. Iversen, E.B.; Moller, J.K.; Morales, J.M.; Madsen, H. Inhomogeneous Markov Models for Describing Driving Patterns. IEEE Trans. Smart Grid 2017, 8, 581-588. [CrossRef]

6. Xu, Y.; Çolak, S.; Kara, E.C.; Moura, S.J.; González, M.C. Planning for electric vehicle needs by coupling charging profiles with urban mobility. Nat. Energy 2018, 3, 484-493. [CrossRef]

7. Zhang, Y.; Zhang, Q.; Farnoosh, A.; Chen, S.; Li, Y. GIS-Based Multi-Objective Particle Swarm Optimization of charging stations for electric vehicles. Energy 2019, 169, 844-853. [CrossRef]

8. Huang, X.; Long, X.; Wang, J.; He, L. Research on parking sharing strategies considering user overtime parking. PLOS ONE 2020, 15, e0233772. [CrossRef]

9. Cai, Y.; Cheng, J.; Zhang, C.; Wang, B. A parking space allocation method to make a shared parking strategy for appertaining parking lots of public buildings. Sustainability 2018, 11, 120. [CrossRef]

10. Krause, J.; Ladwig, S.; Schwalm, M. Statistical assessment of EV usage potential from user's perspective considering rapid-charging technology. Transp. Res. Part. D Transp. Environ. 2018, 64, 150-157. [CrossRef]

11. Švédsko: Základní Charakteristika Teritoria, Ekonomický Přehled. BusinessInfo.cz. Available online: https:// www.businessinfo.cz/navody/svedsko-zakladni-charakteristika-teritoria-ekonomicky-prehled/ (accessed on 5 August 2020).

12. Useable Battery Capacity of full Electric Vehicles Cheatsheet-EV Database. Available online: https: //ev-database.uk/cheatsheet/useable-battery-capacity-electric-car (accessed on 5 August 2020).

13. Energy Consumption of Full Electric Vehicles Cheatsheet-EV Database. Available online: https://evdatabase.uk/cheatsheet/energy-consumption-electric-car (accessed on 5 August 2020).

14. Range of Full Electric Vehicles Cheatsheet-EV Database. Available online: https://ev-database.uk/cheatsheet/ range-electric-car (accessed on 5 August 2020).

15. Price of Full Electric Vehicles Cheatsheet-EV Database. Available online: https://ev-database.uk/cheatsheet/ price-electric-car (accessed on 5 August 2020).

16. Patt, A.; Aplyn, D.; Weyrich, P.; Van Vliet, O. Availability of private charging infrastructure influences readiness to buy electric cars. Transp. Res. Part. A: Policy Pr. 2019, 125, 1-7. [CrossRef]

17. Wang, H.; Chen, S.; Yan, Z.; Ping, J. Blockchain-enabled Charging Right Trading among EV Charging Stations: Mechanism, Model, and Method. Proc. CSEE 2019, 258, 8013. (In Chinese) [CrossRef]

18. Gong, D.; Tang, M.; Buchmeister, B.; Zhang, H. Solving Location Problem for Electric Vehicle Charging Stations-A Sharing Charging Model. IEEE Access 2019, 7, 138391-138402. [CrossRef] 
19. Taljegard, M.; Göransson, L.; Odenberger, M.; Johnsson, F. Impacts of electric vehicles on the electricity generation portfolio-A Scandinavian-German case study. Appl. Energy 2019, 235, 1637-1650. [CrossRef]

20. Pan, L.; Yao, E.; MacKenzie, D. Modeling EV charging choice considering risk attitudes and attribute non-attendance. Transp. Res. Part. C: Emerg. Technol. 2019, 102, 60-72. [CrossRef]

21. Pan, L.; Yao, E.; Yang, Y.; Zhang, R. A location model for electric vehicle (EV) public charging stations based on drivers' existing activities. Sustain. Cities Soc. 2020, 59, 102192. [CrossRef]

22. Sun, S.; Yang, Q.; Yan, W. A Novel Markov-Based Temporal-SoC Analysis for Characterizing PEV Charging Demand. IEEE Trans. Ind. Inform. 2018, 14, 156-166. [CrossRef]

23. Xu, F.; Chen, X.; Zhang, M.; Zhou, Y.; Cai, Y.; Zhou, Y.; Tang, R.; Wang, Y. A sharing economy market system for private EV parking with consideration of demand side management. Energy 2020, 190, 116321. [CrossRef]

24. Lopez-Behar, D.; Tran, M.; Froese, T.M.; Mayaud, J.R.; Herrera, O.E.; Merida, W. Charging infrastructure for electric vehicles in Multi-Unit Residential Buildings: Mapping feedbacks and policy recommendations. Energy Policy 2019, 126, 444-451. [CrossRef]

25. Cost of Charging an Electric Car|Pod Point. Available online: https://pod-point.com/guides/driver/cost-ofcharging-electric-car (accessed on 5 August 2020).

26. Wei, Z.; Li, Y.; Zhang, Y.; Cai, L. Intelligent Parking Garage EV Charging Scheduling Considering Battery Charging Characteristic. IEEE Trans. Ind. Electron. 2018, 65, 2806-2816. [CrossRef]

27. Zhang, L.; Yang, M.; Zhao, Z. Game analysis of charging service fee based on benefit of multi-party participants: A case study analysis in China. Sustain. Cities Soc. 2019, 48, 101528. [CrossRef]

28. Wu, P.; Chu, F.; Saidani, N.; Chen, H.; Zhou, W. IoT-based location and quality decision-making in emerging shared parking facilities with competition. Decis. Support. Syst. 2020, 134, 113301. [CrossRef]

29. Country Detail Vehicles and Fleet Compare|EAFO. Available online: https://www.eafo.eu/countries/europeanunion/23640/vehicles-and-fleet/compare (accessed on 12 August 2020).

30. Friesen, M.; Mingardo, G. Is Parking in Europe Ready for Dynamic Pricing? A Reality Check for the Private Sector. Sustainability 2020, 12, 2732. [CrossRef]

31. Lei, C.; Ouyang, Y. Dynamic pricing and reservation for intelligent urban parking management. Transp. Res. Part. C Emerg. Technol. 2017, 77, 226-244. [CrossRef]

32. Electric Vehicles|Mobility and Transport. Available online: https://ec.europa.eu/transport/themes/urban/ vehicles/road/electric_en (accessed on 8 August 2020).

33. Oblast Severovýchod—Srovnání let a Dnů v Týdnu-Jana Roulichová. Tableau Public. Available online: https://public.tableau.com/profile/jana.roulichova\#!/vizhome/Srovnvacanalza1-PRoblastseverovchod/ DBseverovchod-rokyaweekdays (accessed on 12 August 2020).

34. Emobilita. ŠKO-ENERGO—Hřeje Vás Čistá Energie. Available online: https://www.sko-energo.cz/ content/upload/file/predpokladana_infrastruktura_dobijecich_stanic_pro_mladou_boleslav.pdf (accessed on 16 November 2020).

35. Pareschi, G.; Küng, L.; Georges, G.; Boulouchos, K. Are travel surveys a good basis for EV models? Validation of simulated charging profiles against empirical data. Appl. Energy 2020, 275, 115318. [CrossRef]

36. Test by Germany's Motoring Asscociation Reveals E-Cars Use more Power than Dashboards Show|Clean Energy Wire. Available online: https://www.cleanenergywire.org/news/test-germanys-motoringasscociation-reveals-e-cars-use-more-power-dashboards-show (accessed on 5 October 2020).

37. WHO. Cenové Rozhodnutí Energetického Regulačního Úřadu č. 5/2019 ze dne 26. Listopadu 2019. No. 2019/1. 2019; pp. 1-20. Available online: http://www.eru.cz/documents/10540/6182278/CR_ERU_2020_VVN_ VN_zmeny.pdf/79babf8e-3c25-4e5c-b4e3-1f74a254d731 (accessed on 16 November 2020).

38. WHO. Ceník Elektřiny Pro Podnikatele. No. 2019/1. Prague, 2019; pp. 1-20. Available online: moz-extension://ec5f8c9c-ff7c-0c4e-855f-cea9ed1ceed3/enhanced-reader.html?openApp\&pdf=https\%3A\% 2F\%2Fwww.pre.cz\%2FFiles\%2Ffirmy\%2Felektrina\%2Fseznam-produktu\%2Faktiv-favorit\%2Fcenik-aktivfavorit-3-predi\%2F (accessed on 19 November 2020).

39. Distribuční Sazba D27d: Ideální Při Nabíjení Elektromobilu|Elektřina.cz. Available online: https://www. elektrina.cz/distribucni-sazba-d27d-idealni-pri-nabijeni-elektromobilu (accessed on 6 November 2020). 
40. Proč Olejové Transformátory SGB?|Olejové Transformátory|Elpro-Energo. Available online: https://www. elpro-energo.cz/olejove-transformatory/proc-olejove-transformatory-sgb/ (accessed on 15 September 2020).

Publisher's Note: MDPI stays neutral with regard to jurisdictional claims in published maps and institutional affiliations.

(C) 2020 by the authors. Licensee MDPI, Basel, Switzerland. This article is an open access article distributed under the terms and conditions of the Creative Commons Attribution (CC BY) license (http://creativecommons.org/licenses/by/4.0/). 